\title{
Measuring connectedness of euro area sovereign risk
}

\author{
by Rebekka Buse and Melanie Schienle
}

No. 123 | JANUARY 2019

\section{WORKING PAPER SERIES IN ECONOMICS}

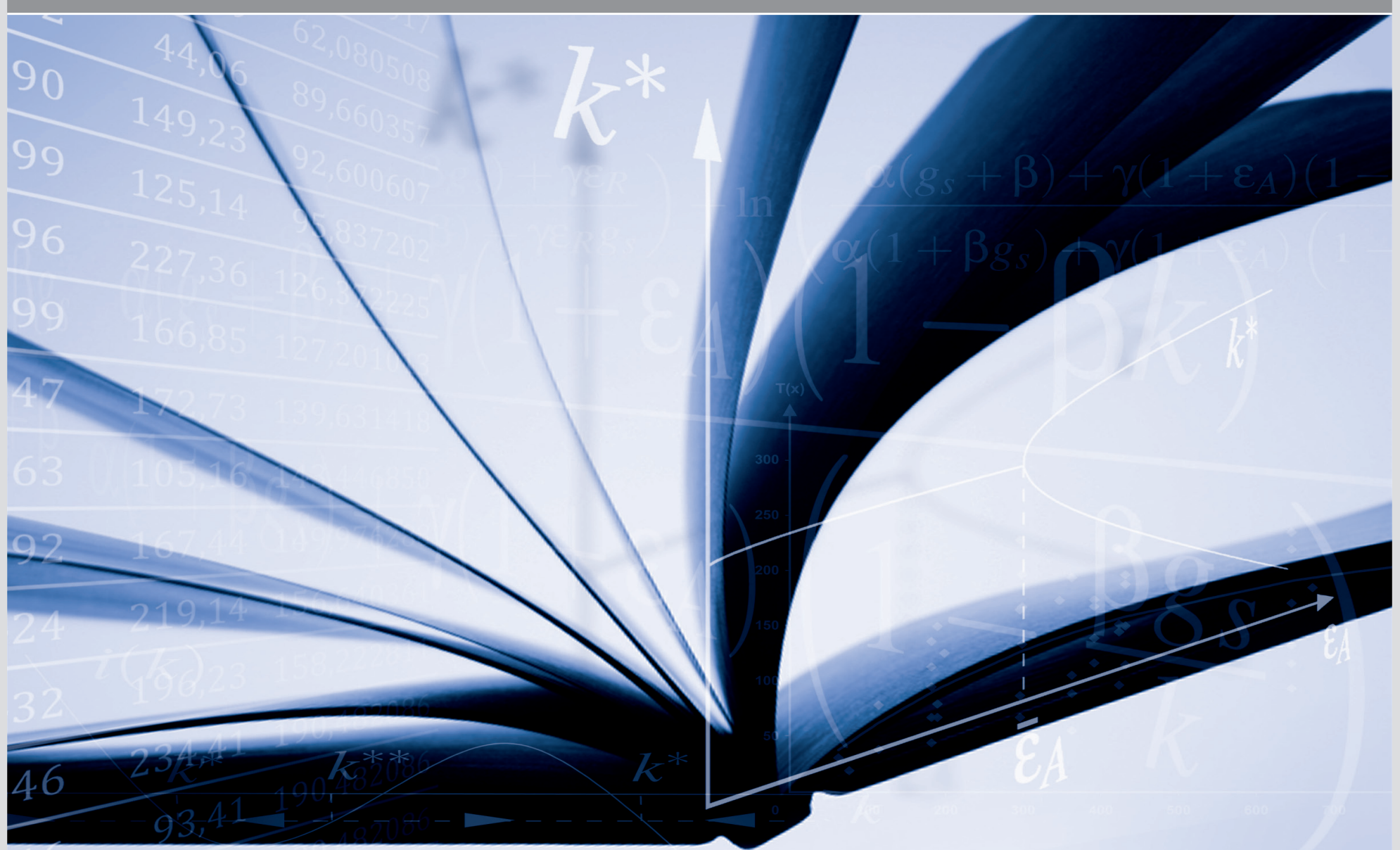




\section{Impressum}

Karlsruher Institut für Technologie (KIT)

Fakultät für Wirtschaftswissenschaften

Institut für Volkswirtschaftslehre (ECON)

Kaiserstraße 12

76131 Karlsruhe

KIT - Die Forschungsuniversität in der Helmholtz-Gemeinschaft

Working Paper Series in Economics

No. 123, January 2019

ISSN 2190-9806

econpapers.wiwi.kit.edu 


\title{
Measuring Connectedness of Euro Area Sovereign Risk
}

\author{
Rebekka Buse $^{a, *} \quad$ Melanie Schienle ${ }^{a}$
}

January 2019

\begin{abstract}
We introduce a method for measuring default risk connectedness of euro zone sovereign states using credit default swap (CDS) and bond data. The connectedness measure is based on an out-of-sample variance decomposition of model forecast errors. Due to its predictive nature, it can respond more quickly to crisis occurrences than common in-sample techniques. We determine sovereign default risk connectedness with both CDS and bond data for a more comprehensive picture of the system. We find evidence that several observable factors drive the difference of CDS and bonds, but both data sources still contain specific information for connectedness spill-overs. Generally, we can identify countries that impose risk on the system and the respective spill-over channels. In our empirical analysis we cover the years 2009-2014, such that recovery paths of countries exiting EU and IMF financial assistance schemes and responses to the ECB's unconventional policy measures can be analyzed.
\end{abstract}

JEL classification: C58, G01, G15, C32

Keywords: Variance decomposition, Sovereign risk, Connectedness, Credit default swaps, Bonds, Eurozone crisis

\footnotetext{
${ }^{a}$ Karlsruhe Institute for Technology, Institute of Economics (ECON), Econometrics and Statistics, Blücherstraße 17, 76185 Karlsruhe, Germany; Emails: rebekka.buse@kit.edu (R. Buse) and melanie.schienle@kit.edu (M. Schienle).

* Corresponding author.
}

This research was supported by the Deutsche Forschungsgemeinschaft through grant SCHI-1127 and data access via CRC 649 "Economic Risk". 


\section{Introduction}

We propose an out-of-sample empirical procedure for assessing how European sovereign states are interconnected through default risk in terms of variance spill-over effects similar to that of Diebold and Yilmaz (2014), Measuring changes in comovements, our method can also be regarded as assessing a specific form of contagion (see e.g. Rodriguez, 2007; or Forbes and Rigobon, 2002) 1 C Contagious interconnection effects among banks and sovereigns have been central drivers of the recent financial and European sovereign crisis. While there already exist many empirical tools and studies analyzing spill-over effects, e.g. Diebold and Yilmaz (2014), Billio et al. (2012), or Engle et al. (2015) and Hautsch et al. (2014) among others, our novel measure is tailored for forecasting with a parsimonious time series approach via variance decomposition. The procedure is easy to apply and based on the forecast error variance, which more adequately reveals the extent and timing of volatility spill-over effects, in particular, around unexpected events. Furthermore, we measure sovereign connectedness with both credit default swap (CDS) and asset swap spreads and find that they contain complementary information of variance-based interconnections.

Technically, we provide an empirical method based on variance decomposition for measuring connectedness between shocks in sovereigns. Our technique captures various aspects of shocks by decomposing out-of-sample forecast errors of a vector autoregression (VAR). Thanks to the out-of-sample approach, the forecast error variance covariance structure can pick up new information more quickly than techniques based on pure in-sample fits such as in Diebold and Yilmaz (2014). The obtained components of the forecast error variancecovariance matrix reveal the interconnectedness among all cross-sectional entities with respect to the volatility channel. We jointly assess connectedness relative to country risk, but also in absolute terms for a more comprehensive picture of the situation. This complements other empirical studies (Alter and Beyer, 2014, e.g.) which discard important information with just relative measures only until mid 2012.

We empirically investigate CDS spreads of eight Eurozone countries (Belgium, France, Germany, Ireland, Italy, Netherlands, Portugal, Spain) from the beginning of 2009 until February 2014. The sample thus covers the sovereign crisis and beyond, in particular not only including country-specific bailout events for Ireland, Portugal and Greece but also Draghi's speech "whatever it takes..." in July 2012 and the ECB's announcement of unconventional

\footnotetext{
${ }^{1}$ There are numerous definitions of specific forms of financial contagion in the literature. We study the predicted impact of an idiosyncratic shock in default risk of one country on the default risk of other countries.
} 
monetary policy measures from 2012 onwards. Our sample allows to take into account the aftermath of the sovereign debt crisis.

We employ both CDS spreads and asset swap (ASW) spreads of bonds for assessing sovereign risk from connectedness. We use asset swaps instead of bond yields as they are free of interest rate risk and thus provide a better comparison to CDS. When measuring contagion purely in returns disregarding connectedness aspects, CDS and bond data lead to similar results (see e.g. Caporin et al., 2013). In variance decomposition results, however, there are important differences across the two types of data. From the beginning of the sovereign crisis onwards, the overall level of connectedness of CDS spreads is substantially higher than that of asset swap spreads. Also, the evolution of country-wise spill-overs on the system reveals different roles of the core countries, Germany, France, Netherlands or Belgium in comparison to the remaining four periphery countries. The latter are captured quite differently for CDS and ASW data and thus reveal different economic and market aspects of the countries. This is also confirmed by contrasting absolute and relative connectedness components which gives information about the share of volatility of a country contributed to the system relative to idiosyncratic volatility. In particular, both sources of data shed different light on the recovery paths of Portugal and Ireland during the crisis in comparison to Spain and Italy where the EU and the IMF did not intervene. Moreover, in terms of effective volatility risk spill-over channels, detected ASW connections can help to focus on the most relevant effects of the dense CDS network which prevail until after the announcement of the OMT. We find that most of the differences in connectedness of ASW and CDS can be explained by bond liquidity, risk aversion and crisis-related events. Although CDS account for risk-related factors driving connectedness, bonds are important for determining a country's risk level compared to other countries. Thus, both datasets should be used to obtain a comprehensive picture of connectedness in the system.

As far as the model is concerned, Diebold and Yilmaz $(2009,2014)$ are the first to use variance decomposition for measuring connectedness. We extend their methodology by including out-of-sample shocks in order to capture all connectedness effects of volatility type more quickly and thereby enhancing measurement quality. There are various extensions of Diebold and Yilmaz (2009), These are complementary to our work with a focus on out-of-sample forecast error variance and the joint analysis of CDS and bonds: Alter and Beyer (2014), Heinz and Sun (2014) and Claeys and Vašíček (2012) analyze connectedness of European sovereigns, while Schmidbauer et al. $(2012,2013)$ and Antonakakis et al. (2016) measure 
connectedness between other entities.

For the data, there has been extensive research on the comparison of CDS and bonds in levels (such as e.g., Longstaff et al., 2011; Delatte et al., 2012; Fontana and Scheicher, 2016; Palladini and Portes, 2011; Gyntelberg et al., 2013; among others) but not on their volatility (the only exceptions are Caporin et al. (2013) and Lange et al. (2016)). To our knowledge, we are the first to compare a second moment measure such as variance decomposition for these two sources of credit quality of a country. This also complements many empirical papers studying contagion in European sovereigns which generally focus on just one type of data, either bonds or CDS. There is also a broad scope of literature examining the price discovery process in CDS and bond markets (such as e.g., Ehrmann and Fratzscher, 2017; Heinz and Sun, 2014). For the differences in the dynamics of levels of CDS and asset swap spreads, several papers have determined important factors such as market frictions like counterparty risk, market illiquidity and funding costs (Arce et al., 2013), but also flight to liquidity effects at the height of the crisis and limits to arbitrage (Fontana and Scheicher, 2016, De Santis, 2014) as well as changes in risk attitude (Calice et al., 2015). We find that for volatility spill-overs, these factors also play an important role, but both measures still contain peculiar information for interconnectedness of European sovereigns.

Furthermore, our paper contributes to the literature on systemic risk and contagion. Several papers measure systemic risk by investigating the situation of one entity conditional on the entire system or market being under distress. For example, Adrian and Brunnermeier (2016) propose the CoVaR and Engle et al. (2015) utilize a Dynamic Conditional Correlation (DCC) model. Acharya et al. (2017) introduce the concept of Systemic Expected Shortfall (SES) and Brownlees and Engle (2017) develop the Marginal Expected Shortfall (MES). Hautsch et al. $(2014,2015)$ propose the realized systemic risk beta using tail risk exposures. Another approach for measuring connectedness uses principal component analysis and Granger-causality tests (Billio et al., 2012; Kalbaska and Gatkowski, 2012). Further approaches include principal component analysis (Arghyrou and Kontonikas, 2012) and impulse responses in a Markov-switching framework (Guidolin and Pedio, 2017). Ricci and Veredas (2015) propose a metric that is based on a tail interquantile range and Schwaab et al. (2011) estimate measures for systemic risk using a mixed-measurement dynamic factor model approach. Giudici and Spelta (2016) and Bianchi et al. (2015) use graphical models to evaluate systemic risk.

The remainder of the paper is organized as follows. In Section 2, we explain the methodo- 
logy. Section 3 describes the data. The empirical results are discussed in Section 4. Section 5 concludes.

\section{Model}

\subsection{Forecast Error Variance Decomposition}

In the following, we assess spill-over effects between countries by fitting an appropriate dynamic specification for the system first, and then studying the variance decomposition of the remaining errors. Variance decompositions generally allow to quantify the effect of a shock in one variable on the variance of another one. In contrast to Diebold and Yilmaz (2014), we base our analysis on out-of-sample forecast errors instead of in-sample errors which are generated in a rolling window approach.

Thus, we first model returns as a vector autoregressive model (VAR)-type process with the following baseline specification:

$$
\mathbf{y}_{t}=\sum_{i=1}^{p} A_{i} \mathbf{y}_{t-i}+\mathbf{u}_{t}, \quad t=1,2, \ldots, T_{e}
$$

where the $(K \times 1)$ vector $\mathbf{u}_{t}$ of error terms is assumed to be a white noise process with $E\left(\mathbf{u}_{t}\right)=$ $\mathbf{0}, E\left(\mathbf{u}_{t} \mathbf{u}_{t}^{\prime}\right)=\Sigma_{u}$ with elements $\sigma_{i j}$ and $E\left(\mathbf{u}_{t} \mathbf{u}_{s}^{\prime}\right)=0$ for $t \neq s . \mathbf{y}_{t}=\left(y_{1 t}, y_{2 t}, \ldots, y_{K t}\right)^{\prime}$ denotes a $(K \times 1)$ vector containing data of $K$ countries and is covariance stationary with moving average representation $\mathbf{y}_{t}=\sum_{i=0}^{\infty} \Phi_{i} \mathbf{u}_{t-i}$. $A_{i}$ represents the $(K \times K)$ matrices of the autoregressive coefficients for $i=1,2, \ldots, p$. In order to obtain forecast errors over time, we fit the dynamic specification in rolling windows with a window width $T_{e}$ for the estimation period of the VAR. In Section 4.1, we provide empirical evidence that for the relatively short window sizes in practice, a VAR-type model specification is sufficient to capture the dynamics of CDS and asset swap returns. On the basis of the estimated VAR coefficients, we can estimate the $H$-step forecast error variance or mean squared error (MSE), defined as:

$$
\Sigma_{y}^{O U T}(H):=M S E\left[\hat{\mathbf{y}}_{t}(H)\right]=E\left[\left(\mathbf{y}_{t+H}-\hat{\mathbf{y}}_{t}(H)\right)\left(\mathbf{y}_{t+H}-\hat{\mathbf{y}}_{t}(H)\right)^{\prime}\right]
$$

where $\hat{\mathbf{y}}_{t}(H)$ is the linear minimum MSE predictor at time $t$ with forecast horizon $H$ obtained from the estimated coefficients $\hat{A}_{i}$ of the proces: 2 , Note that $\hat{\mathbf{y}}_{t}(H)$ is computed only with data from within the estimation sample which does not contain $\mathbf{y}_{t+H}$. Therefore, $\mathbf{y}_{t+H}-\hat{\mathbf{y}}_{t}(H)$

\footnotetext{
${ }^{2} \hat{\mathbf{y}}_{t}(H)=\sum_{i=1}^{p} \hat{A}_{i} \hat{\mathbf{y}}_{t}(H-i)$. For a detailed representation, see Lütkepohl (2005)
} 
is an out-of-sample forecast error and we call $\Sigma_{y}^{O U T}(H)$ in Equation (2) out-of-sample MSE. A standard estimator for $\Sigma_{y}^{O U T}(H)$ is given by

$$
\hat{\Sigma}_{y}^{O U T}(H)=\frac{1}{T_{s}} \sum_{t=1}^{T_{s}}\left(\mathbf{y}_{t+H}-\hat{\mathbf{y}}_{t}(H)\right)\left(\mathbf{y}_{t+H}-\hat{\mathbf{y}}_{t}(H)\right)^{\prime} .
$$

where $T_{s}$ is the sample size used for estimating $\Sigma_{y}^{O U T}(H)$. This is in contrast to the approach by Diebold and Yilmaz (2014) who base their variance decomposition on an in-sample MSE. They replace the forecast error by the moving average (MA) representation formula given by $\mathbf{y}_{t+H}-\mathbf{y}_{t}(H)=\sum_{h=0}^{H-1} \Phi_{h} \mathbf{u}_{t+H-h}$, which then yields:

$$
\begin{aligned}
\Sigma_{y}^{I N}(H):=M S E\left[\mathbf{y}_{t}(H)\right] & =E\left[\left(\mathbf{y}_{t+H}-\mathbf{y}_{t}(H)\right)\left(\mathbf{y}_{t+H}-\mathbf{y}_{t}(H)\right)^{\prime}\right] \\
& =\sum_{h=0}^{H-1}\left(\Phi_{h} \Sigma_{u} \Phi_{h}^{\prime}\right)
\end{aligned}
$$

where $\mathbf{y}_{t}(H)$ is the theoretical optimal predictor for known $\Phi \unlhd^{3}$ and $\Phi_{h}$ is the $h$-th coefficient of the MA-representation. This formula is computed with observations only within the estimation sample, namely the residual covariance matrix $\Sigma_{u}$ and the MA coefficients $\Phi_{h}$. Hence, it is an in-sample forecast error variance. An estimate is obtained using respective estimates $\hat{\Sigma}_{u}$ and $\hat{\Phi}_{h}$.

The out-of-sample MSE is directly computed from the VAR-estimates $\hat{A}_{i}$, whereas the in-sample MSE requires transforming the latter into the MA-representation. In-sample forecast errors use the same sample for estimating the MA-representation and for forecasting. Measures of spill-over effects, however, are mostly intended to deliver a basis for future decisions. In this sense, risk measures derived from the out-of-sample MSE provide a more reliable basis for practical forecasting purposes. Out-of-sample forecast errors separate the estimation sample from the prediction and therefore contain all aspects of potential shocks of predictions. The formulas show that the out-of-sample MSE contains additional variation that is not contained in the in-sample MSE due to unknown future shocks. We show empirically in Section 4.2 .1 that this plays an important role when unexpected events occur. 4

\footnotetext{
${ }^{3}$ In MA-representation: $\mathbf{y}_{t}(H)=\sum_{i=H}^{\infty} \Phi_{i} \mathbf{u}_{t+H-i}$.

${ }^{4}$ Another possibility for representing forecast error variances that are more realistic than the in-sample MSE is the asymptotic approximation of the MSE for estimated processes. However, it is not possible to decompose the approximate MSE because it is an asymmetric sum.
} 
From the $H$-step in-sample MSE we derive the $i j$-th generalized variance decomposition component for a forecast error $H$ periods ahead 5 given by

$$
s_{i j}^{I N}(H)=\frac{\sigma_{j j}^{-1} \sum_{h=0}^{H-1}\left(e_{i}^{\prime} \Phi_{h} \Sigma_{u} e_{j}\right)^{2}}{\sum_{h=0}^{H-1}\left(e_{i}^{\prime} \Phi_{h} \Sigma_{u} \Phi_{h}^{\prime} e_{i}\right)},
$$

where $\sigma_{j j}$ is the $(j, j)$ element of $\Sigma_{u}$ and $e_{i}$ is a selection vector with unity as its $i$-th element and zeros elsewhere. The elements $s_{i j}^{I N}(H)$ for $i, j=1, \ldots K$ are summarized in the connectedness matrix $S^{I N}(H)=\left(\left(s_{i j}^{I N}(H)\right)\right)_{i j}$. The numerator of $s_{i j}^{I N}(H)$ is the contribution of shocks in variable $j$ to the $H$-step forecast error variance of variable $i$. The denominator is the forecast error variance of variable $i$.

For our out-of-sample measure, we decompose the out-of-sample MSE $\Sigma_{y}^{O U T}(H)$ in contrast to the standard in-sample variance decomposition. For the special case of a one step ahead forecast, i.e. $H=1$, the MSE in Equation (4) consists only of one matrix $\Sigma_{y}^{I N}(1)=\Sigma_{u}$, as opposed to MSEs for $H>1$ which are represented by sums of matrices. Since $\Phi_{0}=I_{K}$, it is easy to see that in this special case, Equation (5) simplifies to $s_{i j}^{I N}(1)=\frac{\sigma_{j j}^{-1}\left(e_{i}^{\prime} \Sigma_{u} e_{j}\right)^{2}}{\left(e_{i}^{\prime} \Sigma_{u} e_{i}\right)}=\frac{\sigma_{i j}^{2}}{\sigma_{i i} \sigma_{j j}}$. This shows that variance decomposition components actually are related to squared correlation coefficients of forecast error variances. Generally, for the $i j$-th variance decomposition component of an out-of-sample forecast error $H$ steps ahead, we replace $\Sigma_{u}$ in $s_{i j}^{I N}(1)$ by $\Sigma_{y}^{O U T}(H)$ :

$$
s_{i j}^{O U T}(H)=\frac{\left(e_{i}^{\prime} \Sigma_{y}^{O U T}(H) e_{j}\right)^{2}}{\left(e_{i}^{\prime} \Sigma_{y}^{O U T}(H) e_{i}\right)\left(e_{j}^{\prime} \Sigma_{y}^{O U T}(H) e_{j}\right)} .
$$

Analogously to the in-sample variance decomposition, this is the fraction of variable $i$ 's $H$ step forecast error variance due to shocks in variable $j$ and the individual components are represented in the connectedness matrix $S^{O U T}(H)=\left(\left(s_{i j}^{O U T}(H)\right)\right)_{i j}$. Since the in-sample measure has been used in the literature we also call it standard connectedness.

\subsection{Measures of Connectedness}

We now derive the connectedness $C_{i j}$ marking the volatility spill-over of country $j$ to $i$ from the corresponding variance decomposition elements $s_{i j}^{O U T}$ in (6). In particular, we set

$$
C_{i j}^{O U T}=\frac{1}{3}\left(s_{i j}^{O U T}(1)+s_{i j}^{O U T}(2)+s_{i j}^{O U T}(5)\right)
$$

\footnotetext{
${ }^{5}$ Generalized variance decomposition was proposed by Koop et al. (1996) and Pesaran and Shin (1998) The derivation is shown in the Appendix A.2
} 
to obtain an average over the respective one, two and five step-ahead forecast variance decomposition components. In this way, $C_{i j}^{O U T}$ accounts for both, short and longer term effects of shocks and includes potential feedback effects (see also, e.g. Diebold and Yilmaz (2015) and Alter and Beyer (2014)). We take the standard case as a benchmark and define $C_{i j}^{I N}$ analogously to (7). As in Diebold and Yilmaz (2014), individual connectedness $C_{i j}^{m}$ for $m \in\{O U T, I N\}$ can be gathered for all $i$ and $j$ in Table 1 which then serves as the adjacency matrix determining the underlying network structure. In particular, each element $C_{i j}^{m}$ marks the directed effect of country $j$ on $i$ depicted as the directed edge between the two nodes in the corresponding network graph. We obtain dynamic networks over time by recalculating

\begin{tabular}{cccccc}
\hline & $y_{1}$ & $y_{2}$ & $\cdots$ & $y_{K}$ & \multicolumn{2}{c}{ ingoing } \\
\hline$y_{1}$ & $C_{11}$ & $C_{12}$ & $\cdots$ & $C_{1 K}$ & $\sum_{j=1}^{K} C_{1 j} \quad j \neq 1$ \\
$y_{2}$ & $C_{21}$ & $C_{22}$ & $\cdots$ & $C_{2 K}$ & $\sum_{j=1}^{K} C_{2 j} \quad j \neq 2$ \\
$\vdots$ & $\vdots$ & $\vdots$ & $\ddots$ & $\vdots$ & $\vdots$ \\
$y_{K}$ & $C_{K 1}$ & $C_{K 2}$ & $\cdots$ & $C_{K K}$ & $\sum_{j=1}^{K} C_{K j} \quad j \neq 1 K$ \\
\hline \multirow{2}{*}{ outgoing } & $\sum_{i=1}^{K} C_{i 1}$ & $\sum_{i=1}^{K} C_{i 2}$ & $\cdots$ & $\sum_{i=1}^{K} C_{i K}$ & $\frac{1}{K} \sum_{i, j=1}^{K} C_{i j}$ \\
& $i \neq 1$ & $i \neq 2$ & & $i \neq K$ & $i \neq j$ \\
\hline
\end{tabular}

Table 1: Connectedness Table

The connectedness table depicts connectedness measures on three different aggregation levels; $m$ is omitted for readability.

them for each rolling window. From this granular network structure we obtain the following network statistics which we use to compare the shapes of different networks over time ${ }^{6}$ In particular, country-wise aggregation determines the local importance of a node. We define outgoing connectedness $O C_{j}^{m}$ as a general real-valued version of the degree (see e.g. Barrat et al. (2004)) of node $j$ as

$$
O C_{j}^{m}=\sum_{i=1, i \neq j}^{K} C_{i j}^{m} .
$$

Outgoing connectedness summarizes all individual connectedness that entity $j$ transfers to any other node in the system. Correspondingly, ingoing connectedness $I C_{i}^{m}$ aggregates all connectedness received by $i$ from others by summing row-wise in Table 1:

$$
I C_{i}^{m}=\sum_{j=1, i \neq j}^{K} C_{i j}^{m} .
$$

\footnotetext{
${ }^{6}$ Other network measures such as clustering coefficients and eigenvector centrality require some nodes to be unconnected and thus are not applicable in this setting.
} 
The overall global shape of a network is reflected by its network density 7 . Thus we define total connectedness in line with Diebold and Yilmaz (2014) by aggregating the values of all outgoing and ingoing edges in the network as:

$$
T C^{m}=\frac{1}{K} \sum_{i, j=1, i \neq j}^{K} C_{i j}^{m}
$$

For a more expedient interpretation as weights, the elements of the variance decomposition $S^{m}(H)$ are normalized row-wise before connectedness measures are calculated. In particular, we use

$$
\widetilde{s_{i j}^{m}}=\frac{s_{i j}^{m}}{\sum_{l=1}^{K} s_{i l}^{m}},
$$

where the row sums of the resulting matrix $\widetilde{S^{m}}$ are equal to unity. We denote all measures based on these normalized $\widetilde{s_{i j}^{m}}$ as relative connectedness measures since the impact of $j$ on $i$ is scaled by the total effect of all other $l \neq i$ on $i$. Thus we define as in (7):

$$
\left.\widetilde{C}_{i j}^{O U T}=\frac{1}{3} \widetilde{s_{i j}^{O U T}}(1)+\widetilde{s_{i j}^{O U T}}(2)+\widetilde{s_{i j}^{O U T}}(5)\right)
$$

and also $\widetilde{O C}_{j}^{m}, \widetilde{I C}_{j}^{m}$ and $\widetilde{T C}^{m}$ are obtained accordingly. In this way, we can assess if and how some countries as nodes are more connected than others. For the full picture, we consider both, absolute and relative measures based on $s_{i j}^{m}$ or $\widetilde{s_{i j}^{m}}$ respectively, in order to attribute changes in connectedness to a specific country or the system entity. The connectedness matrices $\widetilde{S^{m}}$ are asymmetric by construction and can be represented as directed network graphs. Note that this is also true for $S^{O U T}$ while the in-sample version $S^{I N}$ is actually symmetric and yields a directed network only through the normalization in $\widetilde{S^{I N}}$.

When clear from the context, the superscript $m \in\{I N, O U T\}$ of a connectedness measure is omitted for improved readability in the rest of the paper.

\section{Data}

Default risk is commonly measured by CDS spreads and asset swap spreads of bonds. We employ daily CDS spreads of nine European countries, including both core and periphery countries: Belgium (BE), France (FR), Germany (DE), Ireland (IE), Italy (IT), Netherlands

\footnotetext{
${ }^{7}$ Weighted density is computed by $\frac{1}{K(K-1)} \sum_{i, j=1, i \neq j}^{K} C_{i j}$.
} 
(NL), Portugal (PT) and Spain (ES) 8 . The CDS are of five years maturity and denominated in US Dollars ${ }^{9}$ The data is retrieved from Bloomberg and covers the time period from 02/02/2009 until 05/02/2014. A CDS transfers the risk of default from the buyer to the seller of the swap. In return, the buyer pays the seller the CDS spread (see Duffie, 1999; Longstaff et al., 2005, Fontana and Scheicher, 2016; among others). Sovereign asset swap spreads are obtained from Thomson Reuters. The sample covers the same set of countries and time period as the CDS data. Like the CDS spreads, the asset swap spreads are for bonds of five years maturity ${ }^{10}$ The reference rate of the asset swap is the three month Euribor and the underlying bonds are denominated in Euro. An asset swap transfers a fixed security, here a sovereign bond, against a floating market rate. This rate minus a reference rate such as the Euribor reflects the creditworthiness of the government issuing the bond, stripped of the interest rate risk. Therefore, the asset swap spread serves as a suitable comparison to CDS spreads (see also Gyntelberg et al., 2013) and should be preferred over bond yield spreads, which include interest rate risk. Figure A.9 in the Appendix shows the levels of CDS spreads and asset swap spreads in comparison.

Tests for stationarity suggest that the data is difference stationary. We apply the Augmented Dickey-Fuller (ADF) test and the Kwiatkowski, Phillips, Schmidt and Shin (KPSS) test to each 200-day subsample of the rolling window. We then compute the percentage of times the $H_{0}$ of the ADF are rejected and the percentage of times the $H_{0}$ of the KPSS cannot be rejected at $5 \%$. This gives us the percentages of 200 -day series that appear to be stationary. Regarding CDS data and according to KPSS, $1.8 \%$ of the level series are stationary and $93.11 \%$ of the return series are stationary on average. Using returns of CDS spreads is common in the literature (cf. Cont and Kan, 2011; Alter and Beyer, 2014; among others). As expected, the statistical properties of asset swap spreads are similar to those of CDS spreads. The results of the KPSS test indicate that $3.6 \%$ of the level data and $99.1 \%$ of the differenced data are stationary. Country-wise summary statistics of spreads and spread returns, as well as the results of the unit root tests, are provided in Table A.6 in Appendix A.1.

\footnotetext{
${ }^{8}$ Greece is excluded from our study because trading of Greek sovereign bonds ceased after the disclosure of its budget deficit on $10 / 20 / 2009$.

${ }^{9}$ In Section 4.2 .3 we control for exchange rate risk among others and find that its effect is negligible.

${ }^{10}$ We use five years maturity in order to make them comparable to CDS spreads, even though bonds of ten years maturity are more liquidly traded, see also Caporin et al. (2013)
} 


\section{Results}

\subsection{Dynamic Specification}

In the underlying rolling window VAR-type specification (1), we aim for a parsimonious model fit while maximizing forecasting power, as our main goal of interest is the connectedness measure based on the forecast error variance decomposition. We obtain the optimal number of lags by minimizing the normed $\mathrm{MSE}^{11}$ of different models for each rolling window. We find that the model generally most suited to our needs is a first order difference VAR with one lag, i.e. a $\operatorname{VAR}(1)$ of spread returns across different estimation and forecast windows $T_{e}, T_{s} \in[100 ; 400]$ with $T_{e} \leq T_{s}$. This coincides also with the in-sample optimal lag length according to AIC. Note that 100 and 400 working days correspond to 4.5 months and 1.5 years of data, respectively. In the following, we take $T=T_{s}=T_{e}$, where $T=200$ corresponds to nine months of data and minimizes the mean MSE across all windows. In this datadriven way, we ensure that windows with $T=200$ are large enough for achieving forecasting accuracy from sufficient estimation precision and small enough to discern past less relevant crisis events ${ }^{12}$ Also, when comparing rolling window in-sample fits via the mean AIC, the MSE-driven choice of $T=200$ performs well and is thus used for the rest of the paper ${ }^{13}$

For a valid connectedness analysis, the dynamic VAR(1) specification must yield unbiased low variance predictions. We therefore benchmark the chosen VAR-model against VECM and VARX alternatives according to out-of-sample MSE performance. The results for the VECM comparison are depicted in Figure A.13 in the Appendix. Even though we find mild evidence for cointegration relationships in a few time periods as indicated by the Johansen test for cointegration, in terms of forecasting power, the first-differenced VAR performs equally well as a respective VECM in non-crisis periods but substantially outperforms it during the crisis. This also corresponds to the intuition that a VECM captures the long term relations between the variables and these become less important during the crisis because agents become more short-sighted 14 There is no improvement in the forecasting power of the VAR by including exogeneous variables controlling for common changes among the CDS spreads, such as change in Euribor reflecting financing conditions, VIX as a proxy for investors' fear and iTraxx

\footnotetext{
${ }^{11}$ Correlation in the forecast error is negligible, thus the properties of optimal forecasts hold for MSE (Patton and Timmermann, 2007).

${ }^{12}$ See Figure A.10 in Appendix A.4.1 for details.

${ }^{13}$ exemplary values of mean AIC: 19.9/17.5/23.6 for a window sizes of $T=200 / 100 / 400$ observations respectively.

${ }^{14}$ This confirms the finding by De Santis (2012) that cointegration models for European Monetary Union (EMU) government bond spread dynamics break down in the period from September 2008 until August 2011.
} 
Europe representing aggregate credit market development Avino and Nneji, 2014 ${ }^{15}$. As illustrated in Figure A.14 in the Appendix, the MSE of the VARX persistently exceeds that of the VAR indicating overall inferior performance of the larger model. For completeness, we also provide the in-sample AIC, BIC and log-likelihood in Table A.8 in the Appendix.

In our connectedness analysis, we are particularly concerned with understanding the effects of specific policy and regulatory announcements and actions, such as country-specific bailout packages, but also EU-wide support programs. The exact dates considered can be found in the timeline in Appendix A.3, which might have also imposed structural breaks in the mean return dynamics. Thus, in order to account for structural breaks we include event dummies that equal unity from the considered events onwards. If our approach was not out-of-sample, breaks could be accounted for by time-varying parameter models as in Giannone et al. (2015). We test for parameter constancy in the underlying VAR model using F-type (Andrews, 1993; Andrews and Ploberger, 1994) and OLS-based MOSUM (Chu et al., 1995 Kuan and Hornik, 1995) stability tests. The p-values of MOSUM-tests are given in Table 2 for both with and without event dummies and $T=200 \sqrt{16}$ The null hypothesis of no structural change is rejected for the country-regressions of Belgium, France and Ireland at the 0.05-level in the VAR without event dummies. On the other hand, the null cannot be rejected at least at the 0.1-level for the model containing event dummies. Hence, we observe no further evidence for structural breaks after including time dummies to the model.

\begin{tabular}{rllllllll}
\hline & Belgium & France & Germany & Ireland & Italy & Netherlands & Portugal & Spain \\
\hline w/o dum & 0.021 & 0.029 & 0.098 & 0.046 & 0.235 & 0.134 & 0.068 & 0.185 \\
w/ dum & 0.274 & 0.318 & 0.338 & 0.628 & 0.525 & 0.157 & 0.510 & 0.677 \\
\hline
\end{tabular}

Table 2: P-values of MOSUM stability test

Under the null hypothesis of no structural break the limiting process for the empirical MOUSM proecess is a standard Brownian bridge. The MOSUM stability test is applied for each equation (i.e. country) of the VAR with a window width of 200 . The first line represents p-values of the MOSUM test for a VAR without event dummies and the second line shows p-values of the MOSUM test for a VAR including event dummies.

Regarding the F-type test, we apply the supF-statistic, which is the most sensitive to structural change among those proposed by Andrews (1993) and Andrews and Ploberger (1994). The F-test is applied for each rolling window of length 200 and the means of the corresponding p-values for each country are given in Table 3. Once again, we observe larger p-values for the model with event dummies, underlining their importance. We therefore

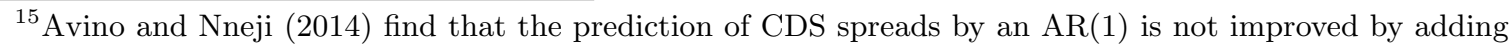
the employed exogenous variables.

${ }^{16}$ For robustness, the MOSUM stability tests are also carried out for window sizes 130, 260 and 400 . The results for these window sizes are similar and are provided upon request.
} 


\begin{tabular}{rllllllll}
\hline & Belgium & France & Germany & Ireland & Italy & Netherlands & Portugal & Spain \\
\hline w/o dum & 0.184 & 0.186 & 0.17 & 0.185 & 0.309 & 0.131 & 0.205 & 0.272 \\
w/ dum & 0.8 & 0.82 & 0.812 & 0.684 & 0.748 & 0.786 & 0.666 & 0.785 \\
\hline
\end{tabular}

Table 3: P-values of supF test statistic

The null hypothesis of no structural change is rejected when the maximal $F$ statistic of all potential break points gets too large. The p-values shown in the table are the country-wise means of the p-values for the sup $F$-statistic across all rolling windows of length 200.

finally stick to a VAR(1) model with event dummies at the specifically considered dates listed in Appendix A.3. The resulting connectedness measures are only mildly affected by the inclusion of time dummies at the event dates ${ }^{17}$, which might be attributed to the relatively short estimation windows (see also Blatt et al., 2015).

As in the literature on connectedness effects (see Diebold and Yilmaz (2014) and Antonakakis et al. (2016), among others), we aim at capturing all unconditional variance spill-over effects with our measures. Therefore, conceptually, pre-filtering for idiosyncratic heteroskedasticity is not required. The results, however, would not differ substantially if pre-filtering was applied. In particular, for the relatively small rolling window estimation sizes of $T=200$ and with event dummies, heteroscedasticity effects play only a minor role. We apply the ARCH-LM-test by (Engle, 1982) to each estimation window and find that we cannot reject the null of no heteroscedasticity (ARCH disturbances) at the 5\%-level (1\%-level) in more than $62 \%(81 \%)$ of the cases (see Figure A.12a in Appendix A.4.3 for a boxplot of all p-values). Furthermore, as a simple validity check, we have recalculated the total connectedness after GARCH pre-filtering and plotted it against the unfiltered total connectedness in Figure A.12b in the Appendix. The results are almost identical.

\subsection{Results on Sovereign Connectedness}

\subsubsection{Advantages of the Out-of-Sample Measure}

In the following, we provide evidence that the novel out-of-sample technique provides significant additional information relative to the standard in-sample method by Diebold and Yilmaz (2014), in particular, it responds more quickly to unforeseen events.

First, we determine significant differences between the novel out-of-sample connectedness and the standard in-sample method by Diebold and Yilmaz (2014) with a Diebold-Mariano Test (DM-Test) for the same underlying dynamic set-up. We clearly reject the null hypothesis that both coincide at levels below $1 \%$. In particular, we find significant deviations of the level

\footnotetext{
${ }^{17}$ See Figure A.11 in Appendix A.4.2
} 
of forecast errors (maximum p-value $<2.2 \cdot 10^{-16}$ ) as well as when comparing connectedness measures at country-level (maximum p-value $=0.000568)$ and total connectedness $(\mathrm{p}$-value $<$ $\left.2.2 \cdot 10^{-16}\right)$. See Table 4 for detailed p-values of DM-tests of differences in country-wise in-sample and out-of-sample connectedness.

\begin{tabular}{|c|c|c|c|c|}
\hline & $\overline{\text { Belgium }}$ & France & Germal & Ireland \\
\hline p-value & $5.68 \cdot 10^{-4}$ & $9.74 \cdot 10^{-10}$ & $2.31 \cdot 10^{-}$ & $2.30 \cdot 10^{-14}$ \\
\hline & Italy & Nethe & Port & Spai \\
\hline p-value & $1.21 \cdot 10^{-8}$ & $3.87 \cdot 10^{-}$ & $2.69 \cdot 10^{-}$ & $4.18 \cdot 10^{-}$ \\
\hline
\end{tabular}

Table 4: P-values of Diebold-Mariano tests for country-wise connectedness with $H_{0}:(\widetilde{O C})_{j, t}^{O U T}=(\widetilde{O C})_{j, t}^{I N}$ versus $H_{1}:(\widetilde{O C})_{j}^{O U T} \neq(\widetilde{O C})_{j}^{I N}$ for all $j=1, \ldots, 8$.

Second, we find that the level of the out-of-sample measure is generally higher than that of the in-sample measure when unexpected crisis-related events occur (see Figure 1), often responding more quickly to such events. Figure 1 shows boxplots of the aggregated

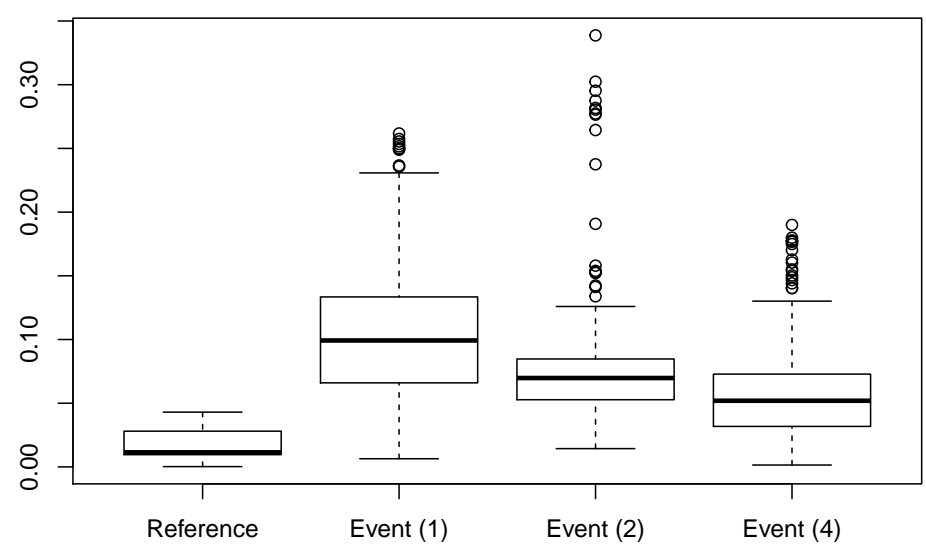

Figure 1: Exemplary boxplots of $\left(\sum_{j=1}^{8} \frac{\left|(\widetilde{O C})_{j, t}^{O U}-(\widetilde{O C})_{j, t}^{I N}\right|}{(\widetilde{O C})_{j, t}^{I N}}\right)$ depicting the aggregated relative difference of country-wise out- and in-sample relative connectedness base don CDS in a window of ten working days before and after bailout dates of selected countries. The event classification follows Table Appendix A.3 The reference period contains the 20 working days in the period 01/12/2012 -02/09/2012 which is not marked by specific events.

relative differences in country-wise out-of-sample and in-sample connectedness around the bailout dates of Ireland (event 1 at 12/01/2010), Portugal (event 2 at 04/06/2011) and Greece (event 4 at 07/21/2011). The differences around these state-specific actions are much larger than those of an exemplary reference period without specific events about 6 months after the last of the three considered events. Moreover, Figure 2 shows for an exemplary core and periphery country the evolution of $(\widetilde{O C})_{j, t}^{O U T}$ and $(\widetilde{O C})_{j, t}^{I N}$ in the upper part and the relative differences in the two lower graphs over the entire time period. Even though the out-of-sample measure often exceeds the in-sample measure, there are also periods were 
France

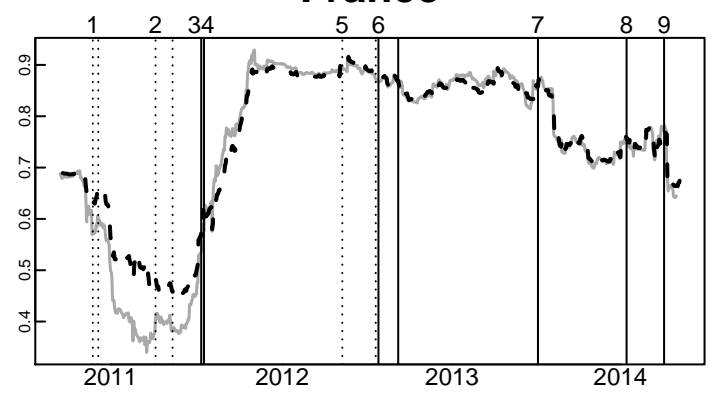

France

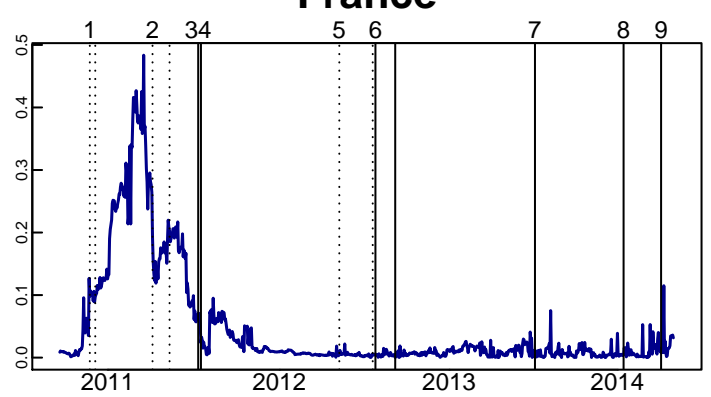

Ireland

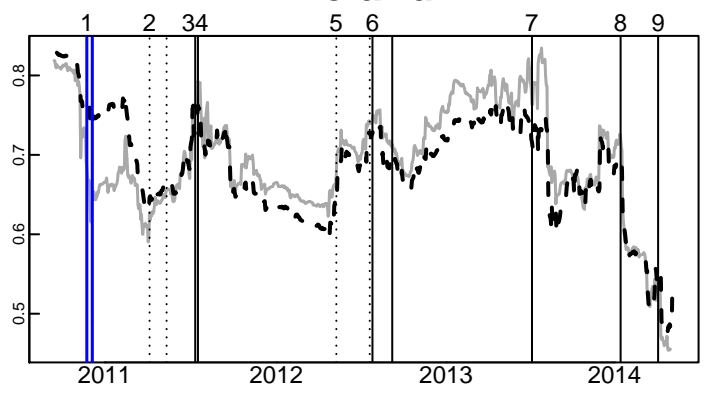

Ireland

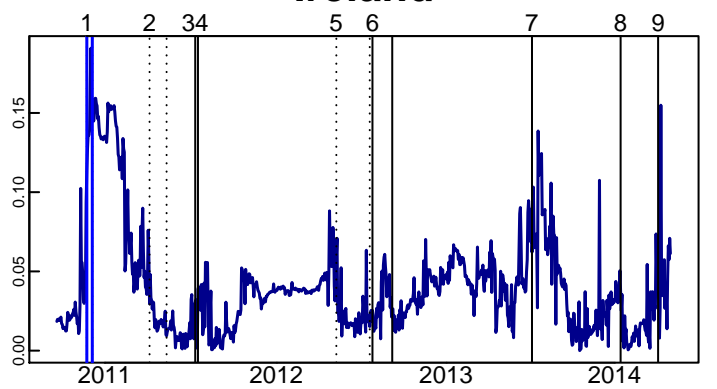

Figure 2: The upper two plots show $(\widetilde{O C})_{j, t}^{O U T}$ in black dashed lines and $(\widetilde{O C})_{j, t}^{I N}$ in grey solid lines for the two countries $j$, where as in the two lower graphs the blue lines depict the relative differences i.e., $\sum_{j=1}^{8} \frac{\left|(\widetilde{O C})_{j, t}^{O U T}-(\widetilde{O C})_{j, t}^{I N}\right|}{(\widetilde{O C})_{j, t}^{I N}}$. All plots are based on CDS data. Important events (see the specification in Table Appendix A.3 are marked with vertical lines with country-specific events in blue.

the contrary is true. Also, the differences between the two measures decrease over time as events become less unexpected. Hence, the use of out-of-sample measures appears preferable in order to obtain more reliable estimates of connectedness, especially, for unexpected key events.

On the network level, we confirm the impression that the out-of-sample measure reacts faster when unexpected events occur. In particular, we compare element-wise differences $\widetilde{C}^{O U T}-\widetilde{C}^{I N}$ for all directed edges in the network at three days around event 4 in Figure 2 which is the bailout of Greece, but also around the bailout of Portugal (event 2, networks shown in Figure A.15) and the announcement of the OMT (event 9, networks shown in Figure A.16). In Figure 3, the CDS-based results for the Greek bailout indicate that out-of-sample connectedness exceeds the in-sample one already before the event picking-up leaking information more quickly. The same is confirmed but less pronounced for asset swaps (Figure A.17). For completeness, we also provide the results for asset swap spreads in Appendix A.6. Differences between CDS and bond data are discussed in detail in the following subsections. 


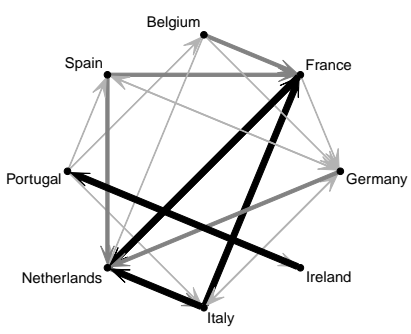

(a) $07 / 20 / 2011$, CDS

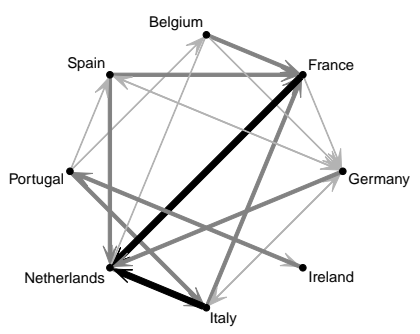

(b) $07 / 21 / 2011$, CDS

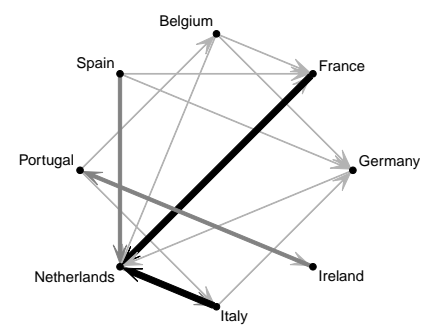

(c) $07 / 22 / 2011$, CDS

Figure 3: The three networks with countries as nodes show $\widetilde{C}_{i j}^{O U T}-\widetilde{C}_{i j}^{I N}$ for $i<j$ depicted by the arrow from $j$ to $i$ and $\widetilde{C}_{i j}^{O U T}-\widetilde{C}_{i j}^{I N}$ for $i>j$ depicted by the arrow from $i$ to $j$ the day before (a), at (b), and the day after (c) a second bailout package for Greece was decided (event 4 in Table Appendix A.3) for CDS data. The thickness of each arrow marks the size of $\widetilde{C}_{i j}^{O U T}-\widetilde{C}_{i j}^{I N}$ according to the following scale: Wide, black arrows correspond to values greater or equal than the third quartile; medium, darkgray edges mark values between the median and third quartile, and thin, lightgray edges show small differences between the first quartile and median. Differences below the first quartile are not shown.

\subsubsection{A Comprehensive Picture of Sovereign Connectedness around Important Events}

We employ our out-of-sample measure for a real-time forecasters' perspective on risk interconnectedness around characteristic events during the crisis. As seen in the previous subsection, the strictly predictive nature of the out-of-sample measure provides appropriate forecasts deviating from those of the standard in-sample analysis by Diebold and Yilmaz (2009) in these cases. In particular, we study the period between February 2009 and 2014 involving country specific bailouts of Ireland, Portugal, Greece, the rescue of Bankia by the Spanish government but also EU wide actions such as Draghi's speech "whatever it takes...", the announcement of the OMT, and further announcements of unconventional ECB monetary policy measures ${ }^{18}$ Note that in all following figures, country specific events appear as blue vertical lines if the respective country is contained in the graphs and in dotted black if not. The most important European-wide events are marked by solid black lines.

CDS connectedness in Figure 4 shows that generally country-wise relative out-connectedness of the four core countries Belgium, France, Germany and the Netherlands drops significantly only after the ECB's commitment to low interest rates (7). Before, connectedness of Germany and the Netherlands is well above $60 \%$. For France and Belgium it is even above $80 \%$. Connectedness of Germany and the Netherlands already begins decreasing after Draghi's speech and the announcement of the OMT (6). While connectedness of Germany and the Netherlands seems unaffected by the bailouts of Ireland (1) and Portugal (2), connectedness of both Belgium as well as France rises during this period of the sovereign debt crisis. Their connectedness measures remain on a high level, comparable to that of Italy, until mid 2013

\footnotetext{
${ }^{18}$ See again Section A.7 in the Appendix for a detailed list.
} 


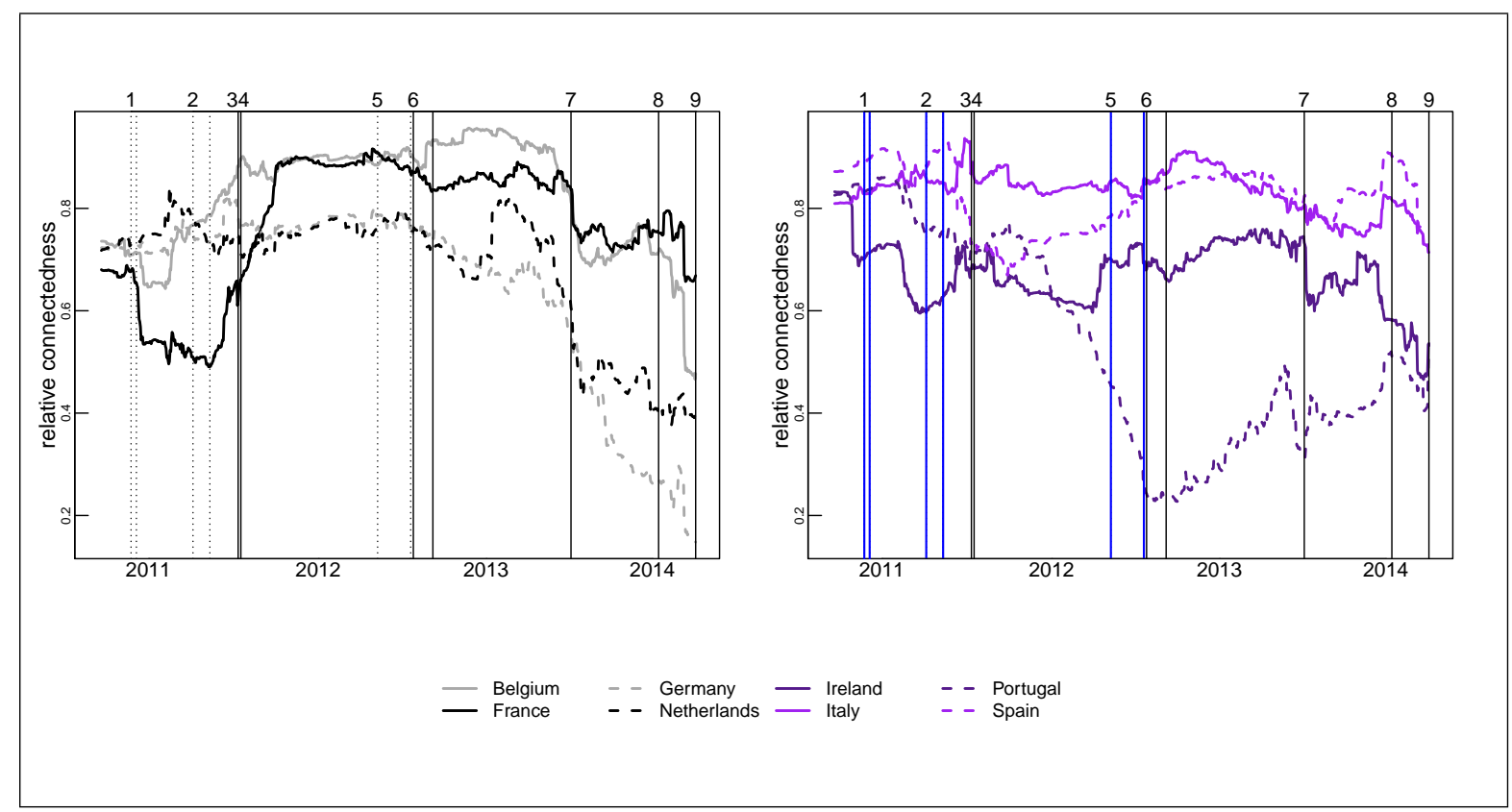

Figure 4: Country-specific outgoing connectedness using relative variance decomposition components for CDS spreads for each country grouped for core countries on the left, and the four periphery countries on the right. Important events are marked with vertical lines. A detailed timeline with their exact specification can be found in the Appendix in Table A.7.

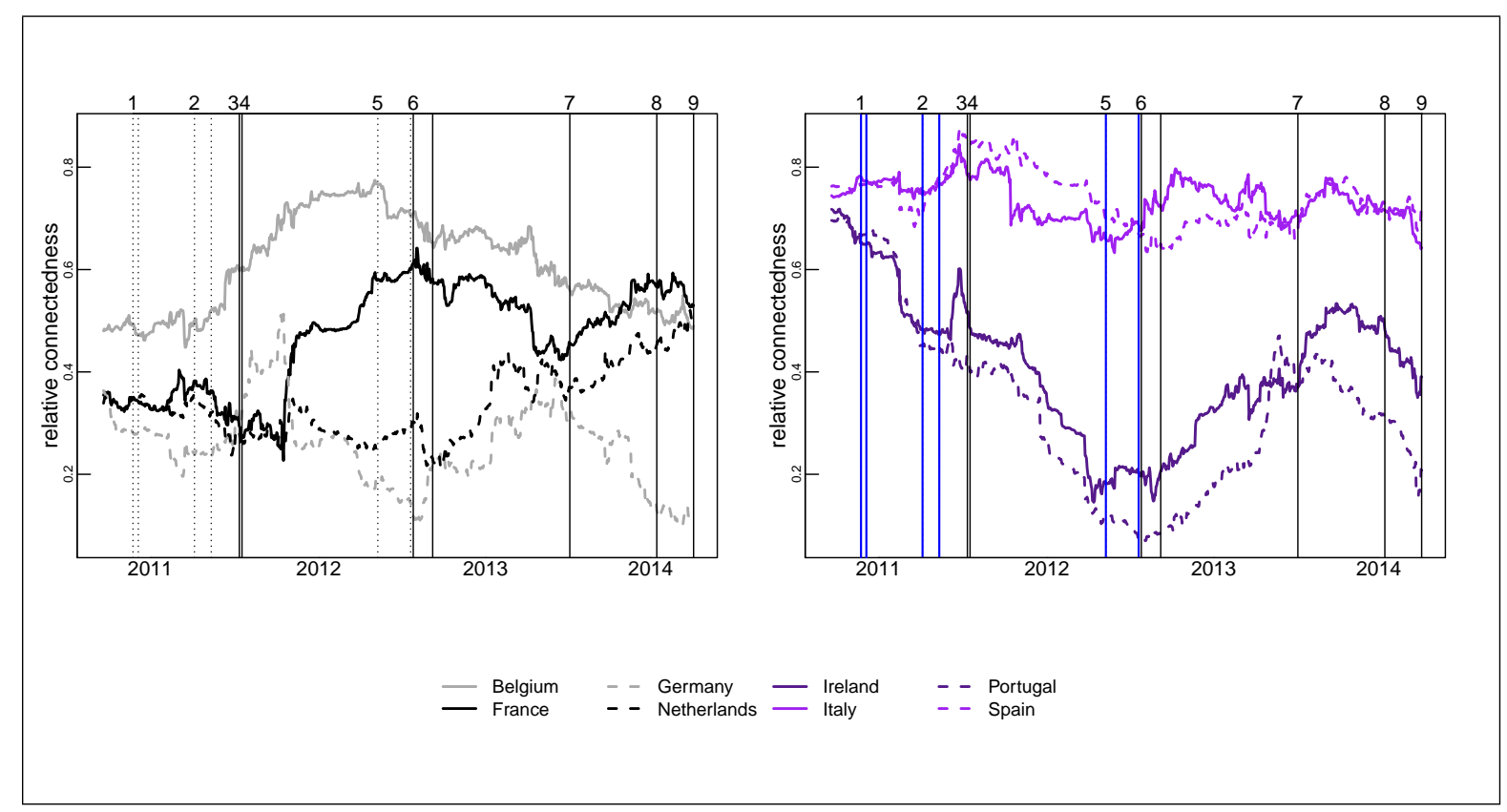

Figure 5: Country-specific outgoing connectedness using relative variance decomposition components for ASW grouped for core coutnries on the left, and the four periphery countries on the right. Important events are marked with vertical lines. Country specific events appear as blue vertical lines if the respective country is contained in the graphs and in dotted black if not. The most important European-wide events are marked by solid black lines. A detailed timeline with their exact specification can be found in the Appendix in Table A.7. 
(7). This reflects the slightly unstable financial situation of France and the impaired banking sector of Belgium.

Among the periphery countries, both Italy and Spain remain on a high level of connectedness which does not decrease until the beginning of 2014, after the European Commission adapts the Risk Finance Guidlines (8). The new guidelines improve SMEs' and midcaps' access to funding and apparently have a stabilizing effect on countries which had been weakened by the crisis. Portugal shows a different behavior from all other countries with connectedness declining sharply between the second bailout for Greece (4) and Draghi's speech (6). This can be explained by fast and effective implementation of austerity measures and structural reforms as e.g. in labor markets and institutions (see e.g European Commission (2014) as well as by reduced speculation and trading in Portugal after the announcement of the naked CDS ban in October 2011. Moreover, Ireland is the only periphery country for which connectedness drops in mid 2013 after (7) similar to the core countries, showing its structural recovery since the turbulence in 2010. The different picture of Ireland's asset swap connectedness in Figure 5 as compared to the CDS based measure can be attributed to the fact that the country actually lost access to market funding in 2010 and entered a financial assistance program by the EU and the IMF until the end of 2013. When exiting the program, the ASW-measure shows that the spill-over impact on other EU-countries quickly decreased as the country managed to fully rely on market based financing restoring market confidence (see IMF (2015)).

Generally, for asset swap connectedness, we observe a defragmentation among the periphery countries' connectedness already from 2011 onwards (see also Ehrmann and Fratzscher, 2017). In CDS connectedness, this becomes visible only from 2014 onwards, after it was clear that restructuring in Portugal and Ireland was successful and both countries could survive without EU and IMF funding schemes. Hence, during the financial assistance periods, the CDS-based measure appears to capture volatility spill-over effects of credit conditions for periphery countries more realistically in terms of economic fundamentals (see also Fontana and Scheicher, 2016). Moreover, relative asset swap connectedness of the four core countries and of Ireland is generally on a lower level than connectedness based on CDS indicating that the bond market captures less volatility spill-overs. While for France and Belgium the dynamics of the asset swap based measure is comparable to CDS connectedness, for Germany and the Netherlands this is not the case. This can be explained by flight to liquidity and flight to quality effects which play an important role for bonds but not for CDS (Fontana and 
Scheicher, 2016). Italy, Spain and Portugal are the only countries for which both, the level as well as the dynamics of outgoing connectedness is similar irrespective of the underlying dataset. Generally, however, when ranking countries by connectedness, the obtained ordering is the same for CDS and ASW for almost all points in time. Nevertheless, differences in the two measures might contain valuable additional information for understanding the role of a country within the system.

A rise in relative connectedness can originate from an increase in absolute individual connectedness or from a decline in absolute ingoing connectedness of that country. Thus, a comparison of the two measures reveals a more comprehensive picture of the spill-over risk each country imposes on the system while only relative levels allow for a connectedness comparison across CDS and ASW data sets. Figure 6 shows the outgoing country-wise CDS connectedness for each country in absolute and relative terms. During the period between the stress test results (3) and the beginning of 2012, Spanish relative connectedness drops, while absolute connectedness only decreases slightly. This shows that absolute ingoing connectedness of Spain increased in this time period which comprises the Greek bailout (4). The opposite behavior of relative and absolute measures occurs for Belgium, France, Ireland, Portugal and Spain after the ECB's commitment to low interest rates (7). For these countries, absolute measures decline more than relative measures, indicating a strong decrease in idiosyncratic volatility.

Draghi's speech marks the point in the crisis after which connectedness for most countries starts an overall decrease. We therefore study this key event in more detail, investigating the spill-over channels on the granular network level. Individual connectedness measures before Draghi's speech and after the announcement of the OMT are visualized in network graphs in Figure 7, in which thicker arrows depict a larger magnitude of connectedness from one country to another. Generally, we observe thinner connections after the announcement of the bond-buying plan but only a few vanish. Hence, while the overall level of connectedness decreases, the effective spill-over channels remain almost entirely active. In the CDS case, only Portugal is less connected to the system confirming its special role detected in the country-wise connectedness also by the network topology. For ASW, there appear much less spill-over channels. The more sparse network, however, contains many strong links of the CDS graph. On the other hand, it also misses out on many valid edges as e.g. between France and Germany, so it could only partially serve as ranking device for the many CDS connections. 


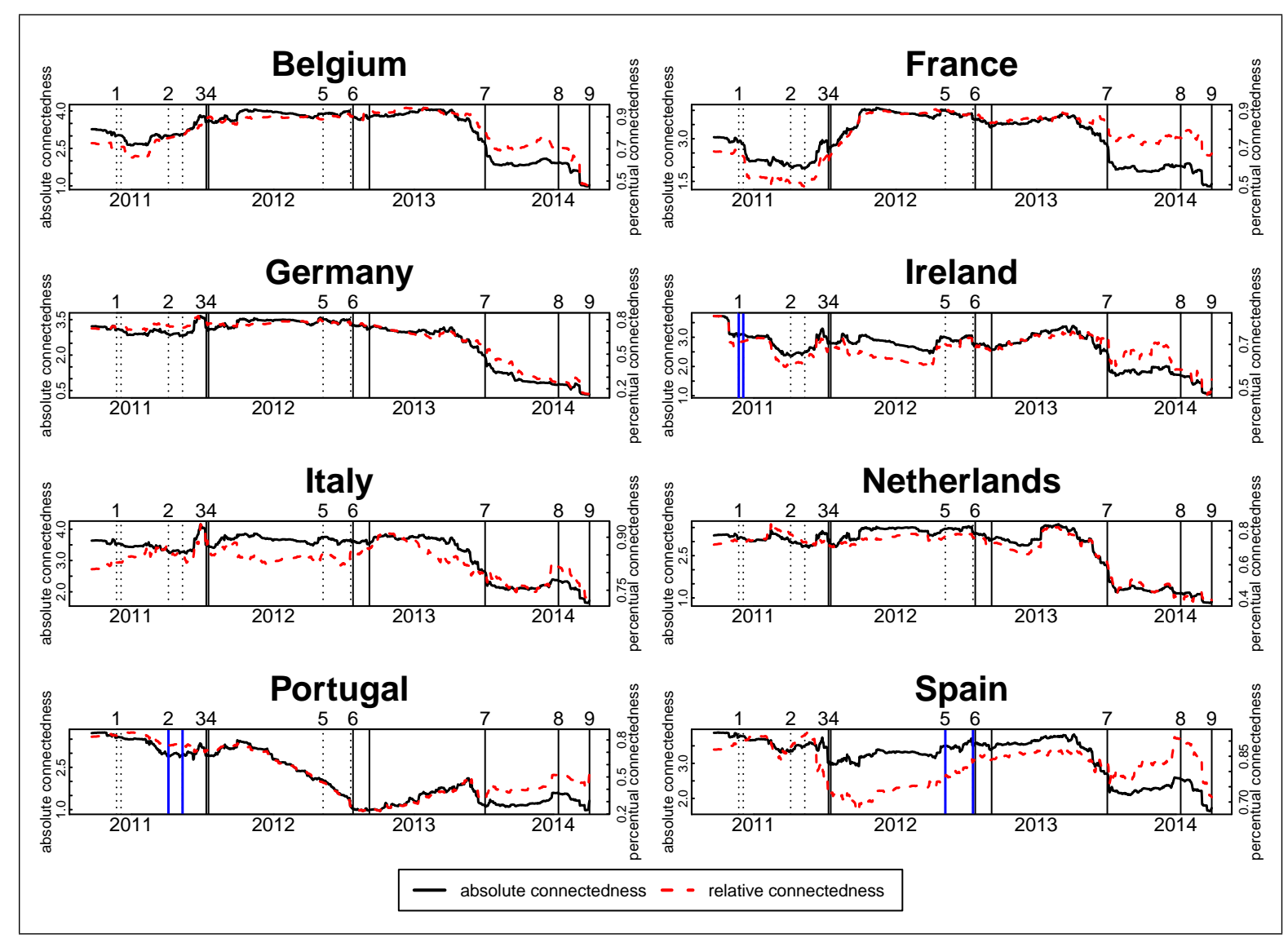

Figure 6: Country-Specific Outgoing Connectedness Using Absolute and Relative Variance Decomposition Components for CDS spreads for each country. Absolute connectedness is depicted by a solid black line and its scale is on the left-hand axis. Relative connectedness is depicted by a dashed line and its scale is on the right-hand axis. Important events are marked with vertical lines. A detailed timeline with their exact specification can be found in the Appendix in Table A.7. The sample period is as in Figure 8.

For absolute individual connectedness, shown in Figure A.18 in the Appendix, CDS networks remain comparable to relative measures, while in the ASW network a strong increase in thin connections is observed. Generally, both absolute measures indicate a stronger decline by the event compared to relative connectedness measures. In particular, this is the case for Ireland, Italy and Portugal which after the ECB's policy announcement affect the system less than before. 


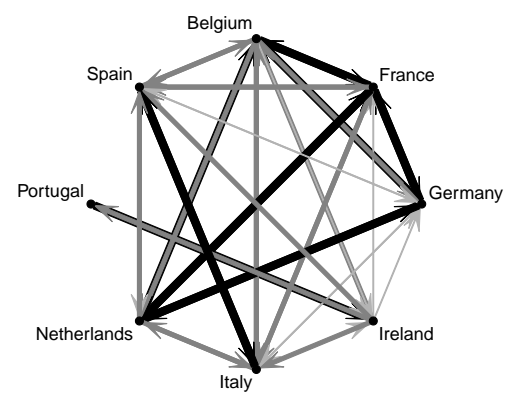

(a) $07 / 25 / 2012$, relative, CDS

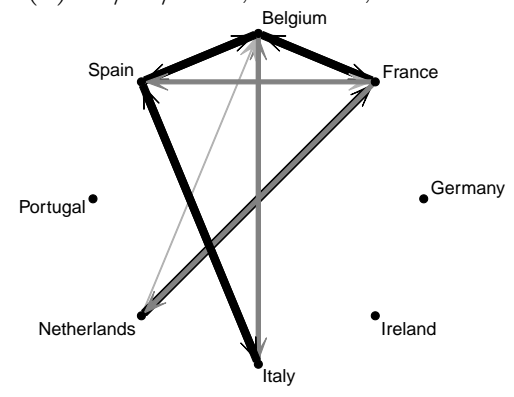

(c) $07 / 25 / 2012$, relative, ASW

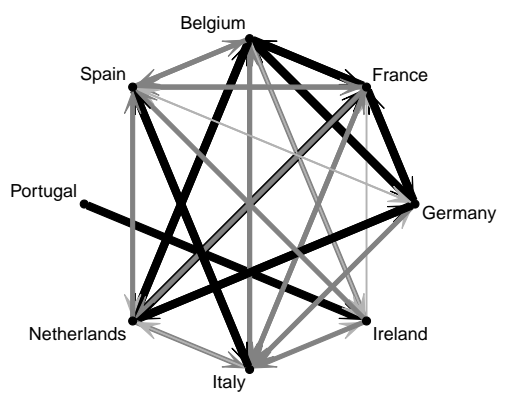

(b) $09 / 07 / 2012$, relative, CDS

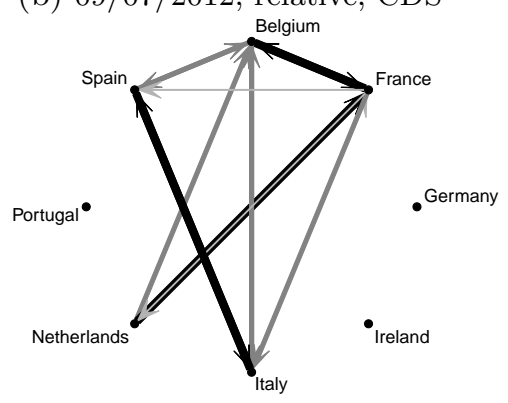

(d) $09 / 07 / 2012$, relative, ASW

Figure 7: Individual relative connectedness before Draghi's speach $(07 / 25 / 2012)$ and after the announcement of the OMT (09/07/2012). The same definitions as in Figure 3 apply. Absolute connectedness is shown in the Appendix in Figure A.18 for completeness.

\subsubsection{Determinants of the Difference in Connectedness of Sovereign CDS versus Asset Swap}

Spreads of Bonds

In the previous two subsections we have seen advantages of the out-of-sample connectedness measure and documented differences between measures based on CDS and asset swap data. Here, we investigate the driving determinants of this discrepancy.

CDS spreads and asset swap or bond yield spreads have both been used in the literature to measure default risk. Since it is well-known that European countries are politically and economically tightly interconnected, CDS and asset swap spreads should react in all countries when crisis-related events occur. Although the theoretic no-arbitrage condition (see Duffie, 1999, among others) would imply that the two datasets reflect the same information on credit risk, we find important structural differences, especially during the crisis. Various research papers have studied the determinants of the difference between CDS and bonds in levels (see e.g. Fontana and Scheicher, 2016, or Bai and Collin-Dufresne, 2011), but only few have compared volatility type measures using both datasets so far (see Caporin et al., 2013 and Lange et al., 2016). Figure 8 illustrates total connectedness of CDS and asset swap spreads. Globally aggregated, variance decomposition measures of asset swap spreads appear to systematically detect less connectedness relative to variance decomposition measures of 
CDS spreads.

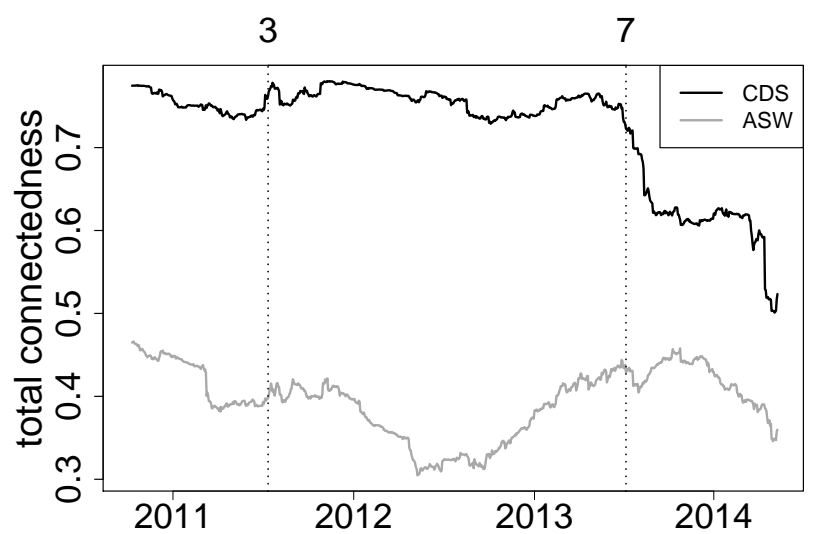

Figure 8: Total relative connectedness of CDS and asset swap spreads. Both are computed with out-of-sample forecast errors and averaged across one, two and five forecast periods ahead. The black line is obtained from CDS spreads and the values resulting from asset swap spreads are depicted by a gray line. The vertical lines marked 3 and 7 (marking the stress test results and the ECB interest rate commitment) designate the period in which the time dummy is used in the panel regression. The sample covers the period from 02/02/2009 until 05/02/2014, which leads to out-of-sample connectedness measures from 08/25/2010 until 05/02/2014.

We investigate the driving determinants of the difference between connectedness measures of CDS and asset swap spreads. We denote this as difference in connectedness and estimate it by a fixed effect panel regression:

$$
z_{j t}=\alpha_{j}+\beta \mathbf{x}_{j t}+\gamma D_{t} \mathbf{x}_{j t}+\varepsilon_{j t}
$$

where $z_{j t}=\sum_{i=1, i \neq j}^{K} \widetilde{C}_{i j, t}^{O U T, C D S}-\widetilde{C}_{i j, t}^{O U T, A S W}$ is the difference in outgoing connectedness for each country $j$ and $\mathbf{x}_{j t}$ represents a vector of explanatory variables. Country fixed effects are captured by $\alpha_{j}$ and the errors $\varepsilon_{j t}$ are independent, strictly exogenous. In order to control for heterogeneity across time, we add a dummy variable $D_{t}$ equal to unity between $07 / 15 / 2011$ (event marked 3) and 07/04/2013 (event marked 7). The regressors contained in $\mathbf{x}_{j t}$ are the bid-ask spread of CDS and bonds, the debt-to-GDP ratio, the VIX and the EuriborEurepo three month spread. All employed determinants are level stationary according to the LR-bar test for multiple cointegration (Larsson et al., 2001). The bid-ask spread is a proxy for liquidity and plays an important role for the difference between CDS and bonds. We use the debt-to-GDP ratio to capture the country's credit quality and the VIX as a global measure for risk aversion. Both the debt-to-GDP ratio and the VIX are expected to have a positive impact on the CDS and asset swap spreads and possibly also on their connectedness measures. The Euribor-Eurepo spread represents arbitrage costs and the general refinancing 
situation: When the repo rate is lower than the Euribor, it is costly to short-sell bonds, thus a high Euribor-Eurepo spread would drive CDS and bonds apart. These factors are jointly significant and are individually more significant than other highly correlated explanatory variables. The regression results are summarized in Table 5.

\begin{tabular}{|c|c|c|c|}
\hline & Variable & Estimate & Std. Dev. \\
\hline \multirow{5}{*}{ 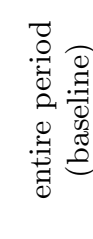 } & Bid-ask CDS & -3.27 & $(1.97)^{\circ}$ \\
\hline & Bid-ask ASW & -1.52 & $(4.37)$ \\
\hline & Debt/GDP & 0.01 & $(0.00)$ \\
\hline & VIX & 0.08 & $(0.02)^{* * *}$ \\
\hline & Euribor-Eurepo & 0.18 & $(0.36)$ \\
\hline \multirow{6}{*}{ 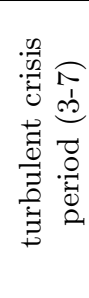 } & Dummy constant & 1.02 & $(0.20)^{* * *}$ \\
\hline & D * Bid-ask CDS & 2.76 & $(0.81)^{* * *}$ \\
\hline & D * Bid-ask ASW & 7.84 & $(2.94)^{* *}$ \\
\hline & $\mathrm{D} *$ Debt/GDP & 0.00 & $(0.00)$ \\
\hline & $\mathrm{D} * \mathrm{VIX}$ & -0.04 & $(0.01)^{* * *}$ \\
\hline & $\mathrm{D}^{*}$ Euribor-Eurepo & 0.13 & $(0.23)$ \\
\hline
\end{tabular}

(a) Estimates and Standard Deviations

\begin{aligned} & \hline Country Fixed Effect \\ & \hline Italy -1.58 \\ & Portugal -1.55 \\ & Ireland -1.39 \\ & Spain -1.38 \\ & Belgium -1.35 \\ & France -1.28 \\ & Germany -1.14 \\ & Netherlands -1.04 \\ & \hline\end{aligned}

(b) Country Fixed Effects in Levels

Table 5: Panel Regression Results

Table 5 a lists the coefficient estimates and standard deviations for the panel regression of the difference in connectedness including fixed effects, using 785 observations of nine countries. The numbers in parentheses are robust standard errors and $* * *, * *, *$ indicate significance at the $0,1 \%, 1 \%$, and $5 \%$ level. The within adjusted R-squared is 0.82 and the coefficients are jointly significant with an $\mathrm{F}$ statistic of 2578.37. Since the difference in connectedness is computed on a 200 day rolling window, we use rolling window estimates of the same width for the regressors. We use a time dummy for the most turbulent period of the crisis between 07/15/2011 (event 3) and 07/04/2012 (event 7). In the second block titled "turbulent crisis period" we list the estimates of the interaction terms. Standard errors are robust to serial correlation and cross-sectional correlation according to Driscoll and Kraay (1998). Countries in Table 5b are ordered by size of the fixed effect.

The difference between the connectedness measures of CDS and bonds is largest during the most turbulent time of the crisis, between 15.07.2011 (event 3) and 04.07.2012 (event 7). The dummy estimate for this period underlines that there is a significant positive shift, which we have already seen earlier in Figure 8. It shows that part of this shift is explained by crisis-related conditions during this period. Apart from the level shift between 2011 and 2013 we also observe a change in the effect of the explanatory variables. Liquidity, proxied by the bid-ask spreads of CDS and bonds, has the largest effect on the difference in connectedness of CDS and asset swap spreads. It is noteworthy that the effect of bond liquidity is only significant during the most turbulent period of the crisis with a total effect of 8.07. The impact of CDS liquidity is almost half the size (-4.32) during more tranquil times compared 
to bond liquidity and decreases to -2.13 between 2011 and 2013 19 Apart from macro factors, liquidity affects the correlation in bond spreads during the crisis (Boffelli et al., 2016). In times of crises, bonds of countries in financial distress are barely traded, whereas bonds of creditworthy countries become more liquid, thus pushing their yields down. The value of CDS, in contrast, depends less on its liquidity. In this sense, flight to quality and flight to liquidity in bond markets during the crisis drive the connectedness measures of CDS and asset swap spreads apart ${ }^{20}$ Fontana and Scheicher (2016) find evidence for the same effect on CDS and bonds in levels. The country fixed effects in Table 5b show that stable countries generally yield higher differences in connectedness, thus confirming the flight to quality or liquidity argument (Beber et al., 2009) . The debt-to-GDP ratio and the VIX both have a smaller, but significant positive impact on the difference in connectedness, meaning that the CDS-based connectedness measure reacts slightly stronger to a change in these variables than the bond-based connectedness measure. The effect of the arbitrage proxy Euribor-Eurepo is insignificant for the difference in connectedness at all times.

We have additionally conducted seperate regressions for CDS connectedness and asset swap connectedness in order to identify advantages of each dataset. Here, $z_{j t}$ corresponds to the outgoing connectedness of country $j$ using CDS or ASW data ${ }^{21}$ The regression results are summarized in Appendix A.5. The asset swap panel regression reveals that the ordering of the country fixed effects are, apart from the position of Belgium, identical to the previous regression of the difference in connectedness. Country fixed effects of CDS connectedness, on the other hand, are not ordered intuitively. This shows that asset swaps are important for determining the approximate position of countries concerning connectedness. While asset swaps play a crucial role for evaluating the position of a country compared to others, CDS connectedness accounts for the factors driving connectedness. Liquidity, the debt-to-GDP ratio and VIX all have a significant impact on CDS connectedness. At the same time, both instruments have drawbacks: Bond liquidity diminishes in the presence of CDS and during the crisis (Massa and Zhang, 2012), while CDS are affected by speculative trading (Oehmke and Zawadowski, 2017). These disadvantages can be compensated by using both instruments simultaneously and thus measure default risk connectedness more precisely.

The complementarity between CDS and asset swap spread connectedness is illustrated on

\footnotetext{
${ }^{19}$ The total effects for the turbulent crisis period equal the sum of the baseline estimates and the dummy interaction estimates.

${ }^{20}$ The difference between CDS and bonds is intensified by ECB bond purchases.

${ }^{21} z_{j t}=\sum_{i=1, i \neq j}^{K} \widetilde{C}_{i j, t}^{O U T, C D S}$ and $z_{j t}=\sum_{i=1, i \neq j}^{K} \widetilde{C}_{i j, t}^{O U T, A S W}$, respectively.
} 
a country level using network graphs in Section 4.2.1 and 4.2.2.

\section{Conclusion}

Interconnectedness has been a crucial element of the financial and European sovereign debt crisis and its propagation. Accordingly, appropriate measures to quantify this interconnectedness are necessary. We provide a method for measuring and forecasting connectedness via the out-of-sample forecast error variance decomposition, which allows for precise measurement results after unexpected events. In contrast to the standard in-sample variance decomposition, our method uses forecast errors predicted for points outside the estimation sample instead of in-sample forecast errors directly computed from the MA representation formula, and it thus incorporates more aspects of unknown shocks. We have shown empirically that around crisis-related events, the out-of-sample measure reflects changes in connectedness faster than the standard variance decomposition as proposed by Diebold and Yilmaz (2014). A detailed comparison at specific events shows that out-of-sample measures are advantageous, especially when using CDS data.

We find, however, that CDS and asset swap spreads contain complementary information for evaluating connectedness. The difference between the respective measures is explained by liquidity effects, credit quality, risk aversion and crisis-related conditions. Asset swaps are important for determining the overall risk position of countries while CDS reflect more detailed information on country-specific risk.

We analyze connectedness in Europe during the sovereign debt crisis by evaluating both relative and absolute connectedness measures. In general, levels of connectedness measures decrease after financial aid packages to impaired countries and the ECB's policy measures, while the channels through which they are transmitted prevail.

In this paper we have shown that out-of-sample connectedness of CDS captures effects of unexpected events instantaneously. The results for CDS and asset swap spreads motivate a look at intra-day data for extracting more precise information on their driving forces. We will explore this in our future work given data availability. 


\section{References}

Acharya, V. V., L. H. Pedersen, T. Philippon, and M. P. Richardson (2017): "Measuring systemic risk," Review of Financial Studies, 30, 2-47.

Adrian, T. And M. K. Brunnermeier (2016): "CoVaR," American Economic Review, $106,1705-41$.

Alter, A. And A. Beyer (2014): "The dynamics of spillover effects during the European sovereign debt crisis," Journal of Banking and Finance, 134-153.

Andrews, D. And W. Ploberger (1994): "Optimal Tests When a Nuisance Parameter Is Present Only under the Alternative," Econometrica, 62, 1383-1414.

Andrews, D. W. K. (1993): "Tests for Parameter Instability and Structural Change with Unknown Change Point," Econometrica, 61, 821-856.

Antonakakis, N., C. Floros, And R. Kizys (2016): "Dynamic spillover effects in futures markets: UK and US evidence," International Review of Financial Analysis, 48, 406 - 418.

Arce, O., S. Mayordomo, and J. I. PeÑa (2013): "Credit-risk valuation in the sovereign CDS and bonds markets: Evidence from the euro area crisis," Journal of International Money and Finance, 35, 124-145.

Arghyrou, M. And A. Kontonikas (2012): "The EMU sovereign-debt crisis: Fundamentals, expectations and contagion," Journal of International Financial Markets, Institutions and Money, 22, 658-677.

Avino, D. And O. NnejI (2014): "Are CDS spreads predictable? An analysis of linear and non-linear forecasting models," International Review of Financial Analysis, 34, 262-274.

Bai, J. And P. Collin-Dufresne (2011): "The determinants of the cds-bond basis during the financial crisis of 2007-2009," SSRN eLibrary.

Barrat, A., M. Barthlemy, R. Pastor-Satorras, and A. Vespignani (2004): "The architecture of complex weighted networks," Proceedings of the National Academy of Sciences of the United States of America, 101, 3747-3752.

Beber, A., M. W. Brandt, And K. A. Kavajecz (2009): "Flight-to-Quality or Flightto-Liquidity? Evidence from the Euro-Area Bond Market," Review of Financial Studies, $22,925-957$. 
Bianchi, D., M. Billio, R. Casarin, And M. Guidolin (2015): "Modeling Systemic Risk with Markov Switching Graphical SUR Models," SSRN eLibrary.

Billio, M., M. Getmansky, A. W. Lo, and L. Pelizzon (2012): "Econometric measures of connectedness and systemic risk in the finance and insurance sectors," Journal of Financial Economics, 104, 535-559.

Blatt, D., B. Candelon, and H. Manner (2015): "Detecting contagion in a multivariate time series system: An application to sovereign bond markets in Europe," Journal of Banking \& Finance, 59, 1-13.

Boffelli, S., V. D. Skintzi, And G. Urga (2016): "High- and Low-Frequency Correlations in European Government Bond Spreads and Their Macroeconomic Drivers," Journal of Financial Econometrics, 15, 62.

Brownlees, C. T. And R. Engle (2017): "SRISK: A Conditional Capital Shortfall Measure of Systemic Risk," The Review of Financial Studies, 30, 48-79.

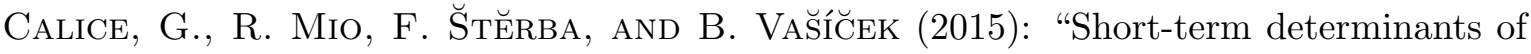
the idiosyncratic sovereign risk premium: A regime-dependent analysis for European credit default swaps," Journal of Empirical Finance, 33, 174 - 189.

Caporin, M., L. Pelizzon, F. Ravazzolo, and R. Rigobon (2013): "Measuring sovereign contagion in Europe," Working Paper 2012/05, Norges Bank.

Chu, C.-S. J., K. Hornik, And C.-M. Kaun (1995): "MOSUM tests for parameter constancy," Biometrika, 82, 603-617.

Claeys, P. And B. Vaš́́̌́CEK (2012): "Measuring Sovereign Bond Spillover in Europe and the Impact of Rating News," Working Papers 2012/07, Czech National Bank, Research Department.

Cont, R. AND Y. H. KAN (2011): "Dynamic hedging of portfolio credit derivatives," SIAM Journal on Financial Mathematics, 2, 112-140.

De Santis, R. A. (2012): "The Euro area sovereign debt crisis: safe haven, credit rating agencies and the spread of the fever from Greece, Ireland and Portugal," Working Paper Series 1419, European Central Bank. 
(2014): "The euro area sovereign debt crisis: Identifying flight-to-liquidity and the spillover mechanisms," Journal of Empirical Finance, 26, 150 - 170.

Delatte, A.-L., M. Gex, And A. Lopez-Villavicencio (2012): "Has the CDS market influenced the borrowing cost of European countries during the sovereign crisis?" Journal of International Money and Finance, 31, 481-497.

Diebold, F. And K. Yilmaz (2009): "Measuring Financial Asset Return and Volatility Spillovers, with Application to Global Equity Markets," Economic Journal, 119, 158-171.

(2014): "On the network topology of variance decompositions: Measuring the connectedness of financial firms," Journal of Econometrics, 182, 119-134.

(2015): Financial and Macroeconomic Connectedness: A Network Approach to Measurement and Monitoring, Oxford University Press.

Driscoll, J. AND A. KraAy (1998): "Consistent Covariance Matrix Estimation With Spatially Dependent Panel Data," The Review of Economics and Statistics, 80, 549-560.

Duffie, D. (1999): “Credit Swap Valuation,” Financial Analysts Journal, 55.

Ehrmann, M. AND M. Fratzscher (2017): "Euro area government bonds Fragmentation and contagion during the sovereign debt crisis," Journal of International Money and Finance, 70, $26-44$.

Engle, R. (1982): "Autoregressive Conditional Heteroscedasticity with Estimates of the Variance of United Kingdom Inflation," Econometrica, 50, 987-1007.

Engle, R., E. Jondeau, and M. Rockinger (2015): "Systemic risk in Europe," Review of Finance, 19, 145-190.

European Commission (2014): "The Economic Adjustment Programme for Portugal 20112014," European Economy Occasional Papers 202, Directorate General for Economic and Financial Affairs.

FontanA, A. AND M. Scheicher (2016): "An analysis of euro area sovereign CDS and their relation with government bonds," Journal of Banking E Finance, 62, 126-140.

Forbes, K. J. And R. Rigobon (2002): "No Contagion, Only Interdependence: Measuring Stock Market Comovements," Journal of Finance, 57, 2223-2261. 
Giannone, D., M. Lenza, And G. E. Primiceri (2015): "Prior Selection for Vector Autoregressions," The Review of Economics and Statistics, 97, 436-451.

Giudici, P. And A. Spelta (2016): "Graphical Network Models for International Financial Flows," Journal of Business \& Economic Statistics, 34, 128-138.

Guidolin, M. And M. Pedio (2017): "Identifying and measuring the contagion channels at work in the European financial crises," Journal of International Financial Markets, Institutions and Money, 48, 117-134.

Gyntelberg, J., P. Hördahl, K. Ters, and J. Urban (2013): "Intraday dynamics of euro area sovereign CDS and bonds," BIS Working Papers 423, Bank for International Settlements.

Hamilton, J. D. (1994): Time Series Analysis, Princeton Universiy Press.

Hautsch, N., J. Schaumburg, And M. Schienle (2014): "Forecasting systemic impact in financial networks," International Journal of Forecasting, 30, 781-794.

Heinz, F. F. AND Y. Sun (2014): "Sovereign CDS Spreads in Europe: The Role of Global Risk Aversion, Economic Fundamentals, Liquidity, and Spillovers," IMF Working Papers 14/17, International Monetary Fund.

IMF (2015): "IRELAND - Lessons from Its Recovery from the Bank-Sovereign Loop," Highlevel conference, European Department.

Kalbaska, A. And M. Gatkowski (2012): "Eurozone sovereign contagion: Evidence from the CDS market (20052010)," Journal of Economic Behavior 83 Organization, 83, 657-673.

Koop, G., M. H. Pesaran, And S. M. Potter (1996): "Impulse response analysis in nonlinear multivariate models," Journal of Econometrics, 74, 119-147.

KuAn, C.-M. AND K. Hornik (1995): "The generalized fluctuation test: A unifying view," Econometric Reviews, 14, 135-161.

Lange, R.-J., A. Lucas, And A. H. Siegmann (2016): "Score-Driven Systemic Risk Signaling for European Sovereign Bond Yields and CDS Spreads," Tinbergen Institute Discussion Papers 16-064/IV, Tinbergen Institute.

Larsson, R., J. Lyhagen, And M. Lthgren (2001): "Likelihood-based cointegration tests in heterogeneous panels," Econometrics Journal, 4, 109-142. 
Longstaff, F. A., S. Mithal, And E. Neis (2005): "Corporate Yield Spreads: Default Risk or Liquidity? New Evidence from the Credit Default Swap Market," Journal of Finance, 60, 2213-2253.

Longstaff, F. A., J. Pan, L. H. Pedersen, and K. J. Singleton (2011): "How Sovereign Is Sovereign Credit Risk?" American Economic Journal: Macroeconomics, 3, $75-103$.

Lütkepohl, H. (2005): New Introduction to Multiple Time Series Analysis, Springer-Verlag.

Massa, M. And L. Zhang (2012): "CDS and the Liquidity Provision in the Bond Market," Faculty and Research Working Paper 2012-14-FIN, INSEAD.

Oenmke, M. And A. Zawadowski (2017): "The Anatomy of the CDS Market," The Review of Financial Studies, 30, 80.

Palladini, G. And R. Portes (2011): "Sovereign CDS and Bond Pricing Dynamics in the Euro-area," NBER Working Papers 17586, National Bureau of Economic Research, Inc.

Patton, A. J. And A. Timmermann (2007): "Properties of optimal forecasts under asymmetric loss and nonlinearity," Journal of Econometrics, 140, 884-918.

Pesaran, H. H. ANd Y. Shin (1998): "Generalized impulse response analysis in linear multivariate models," Economics Letters, 58, 17-29.

Ricci, L. And D. Veredas (2015): "TailCoR," Banco de Espana Working Papers 1227, Banco de Espana.

Rodriguez, J. C. (2007): "Measuring financial contagion: A Copula approach," Journal of Empirical Finance, 14, 401-423.

Schmidbauer, H., A. Rösch, And E. Uluceviz (2012): "Connectedness Cycles in Equity Markets: A Wavelet Approach," Tech. rep., EcoMod.

SchwaAB, B., S. J. Koopman, And A. LuCas (2011): "Systemic risk diagnostics: coincident indicators and early warning signals," Working Paper Series 1327, European Central Bank. 


\section{Appendix A.}

Appendix A.1. Summary Statistics

Belgium

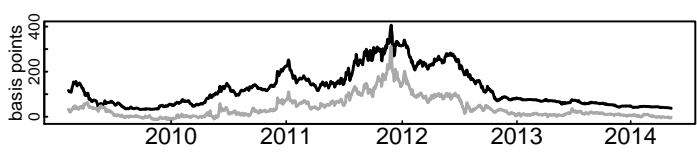

Germany

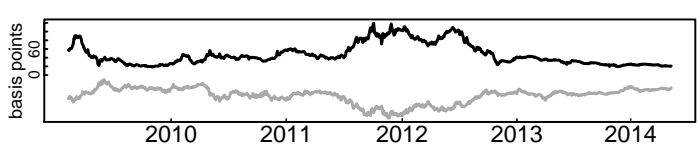

Italy

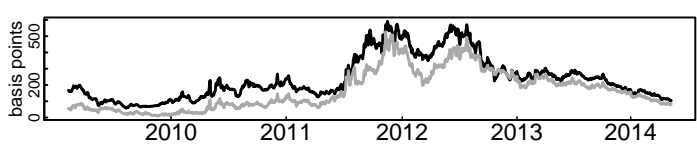

Portugal

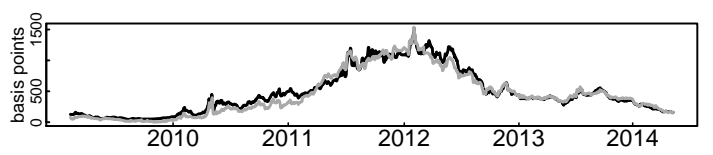

France

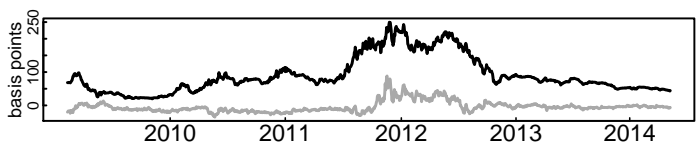

Ireland

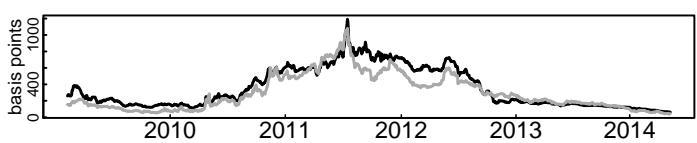

Netherlands

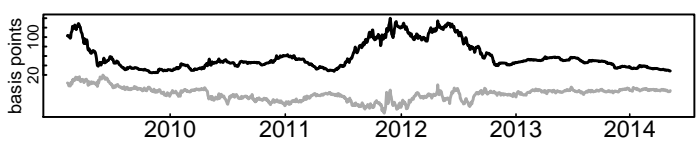

Spain

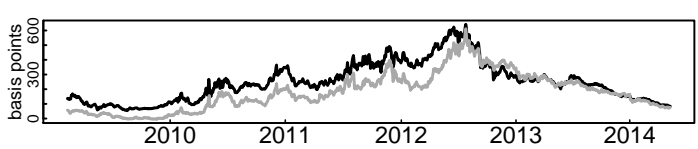

- CDS Spreads _ Asset Swap Spreads

Figure A.9: Levels of CDS and Asset Swap Spreads.

This figure shows CDS spreads plotted with black lines and asset swap spreads plotted with gray lines for each country. The left axis represents the levels of spreads denoted in basis points. The sample covers the period from 02/02/2009 until 05/02/2014. 


\begin{tabular}{|c|c|c|c|c|c|c|c|c|c|c|}
\hline & & & Belgium & France & Germany & Ireland & Italy & Netherlands & Portugal & Spain \\
\hline \multirow{18}{*}{ 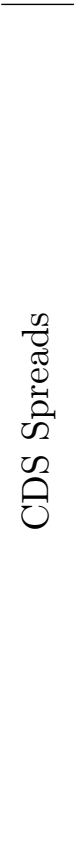 } & \multirow{9}{*}{ 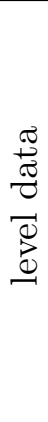 } & Mean & 123.73 & 90.78 & 47.43 & 349.82 & 239.68 & 58.69 & 480.23 & 249.45 \\
\hline & & Median & 87.83 & 75.44 & 40.02 & 223.85 & 199.83 & 48.29 & 395.38 & 237.16 \\
\hline & & $\operatorname{Max}$ & 406.12 & 249.62 & 119.17 & 1191.50 & 591.54 & 139.84 & 1526.95 & 641.98 \\
\hline & & Min & 31.93 & 19.66 & 18.73 & 61.08 & 57.60 & 24.50 & 44.52 & 53.69 \\
\hline & & Std dev & 82.95 & 54.30 & 24.67 & 241.41 & 133.01 & 28.56 & 352.23 & 132.90 \\
\hline & & Skew & -12.97 & -62.35 & -938.35 & 3.54 & 2.40 & -550.74 & 4.19 & 2.67 \\
\hline & & Kurt & 66.62 & 422.05 & 14330.92 & 9.82 & 14.60 & 7138.90 & 11.29 & 15.00 \\
\hline & & $\mathrm{ADF}$ & 17.3 & 10.2 & 10.3 & 16.0 & 4.3 & 10.6 & 10.8 & 5.9 \\
\hline & & KPSS & 0.9 & 3.2 & 2.1 & 1.0 & 6.8 & 1.6 & 0.6 & 1.8 \\
\hline & \multirow{9}{*}{ 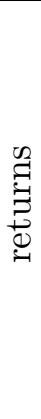 } & Mean & -0.06 & -0.02 & -0.03 & -0.15 & -0.05 & -0.06 & 0.03 & -0.04 \\
\hline & & Median & -0.05 & -0.05 & -0.00 & -0.08 & -0.22 & -0.03 & 0.00 & -0.01 \\
\hline & & $\operatorname{Max}$ & 35.67 & 22.76 & 15.69 & 107.74 & 64.08 & 14.81 & 141.59 & 55.29 \\
\hline & & Min & -59.35 & -30.03 & -14.67 & -146.15 & -80.83 & -15.64 & -159.11 & -73.89 \\
\hline & & Std dev & 6.19 & 4.25 & 2.11 & 14.62 & 11.14 & 2.47 & 21.09 & 11.82 \\
\hline & & Skew & -0.54 & -0.21 & 0.19 & -0.60 & 0.09 & -0.15 & -0.38 & -0.50 \\
\hline & & Kurt & 16.75 & 10.34 & 10.93 & 20.26 & 10.59 & 9.90 & 14.35 & 8.63 \\
\hline & & $\mathrm{ADF}$ & 100.0 & 100.0 & 100.0 & 100.0 & 100.0 & 100.0 & 99.7 & 100.0 \\
\hline & & KPSS & 91.6 & 94.7 & 94.0 & 93.1 & 95.8 & 85.5 & 92.6 & 98.1 \\
\hline \multirow{18}{*}{ 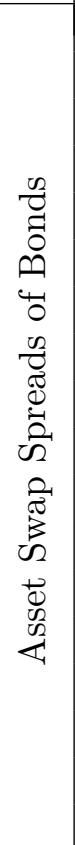 } & \multirow{9}{*}{ 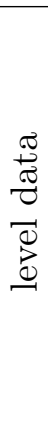 } & Mean & 40.33 & -3.78 & -47.23 & 294.04 & 167.55 & -20.04 & 452.94 & 183.00 \\
\hline & & Median & 22.80 & -6.90 & -42.90 & 210.10 & 131.24 & -18.00 & 386.11 & 172.30 \\
\hline & & $\operatorname{Max}$ & 311.50 & 88.30 & -10.10 & 1080.70 & 526.90 & 19.70 & 1535.70 & 611.80 \\
\hline & & Min & -14.90 & -35.00 & -98.90 & 37.82 & 8.50 & -60.90 & -0.50 & -4.40 \\
\hline & & Std dev & 48.71 & 16.48 & 17.73 & 213.76 & 121.07 & 13.38 & 360.93 & 128.77 \\
\hline & & Skew & -89.75 & -3327.68 & -3767.92 & 5.14 & 2.42 & -7089.41 & 4.87 & 3.13 \\
\hline & & Kurt & 749.87 & 81383.37 & 92189.12 & 16.57 & 22.63 & 219378.36 & 13.41 & 20.85 \\
\hline & & ADF & 26.5 & 22.5 & 2.8 & 17.0 & 3.0 & 0.6 & 10.9 & 8.3 \\
\hline & & KPSS & 0.0 & 15.4 & 12.5 & 0.0 & 0.0 & 8.8 & 0.0 & 1.7 \\
\hline & \multirow{9}{*}{ 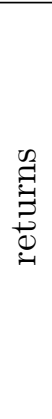 } & Mean & -0.03 & 0.01 & 0.02 & -0.09 & 0.02 & -0.01 & 0.07 & 0.01 \\
\hline & & Median & 0.00 & 0.07 & 0.05 & -0.43 & -0.10 & -0.10 & 0.17 & 0.00 \\
\hline & & Max & 33.10 & 28.30 & 8.70 & 102.80 & 71.60 & 15.30 & 183.40 & 50.90 \\
\hline & & Min & -47.90 & -21.30 & -10.30 & -109.20 & -82.90 & -12.50 & -165.60 & -79.80 \\
\hline & & Std dev & 6.26 & 3.84 & 2.20 & 13.69 & 10.66 & 2.64 & 19.83 & 10.59 \\
\hline & & Skew & -0.29 & 0.09 & -0.08 & -0.43 & -0.35 & 0.18 & 0.55 & -0.93 \\
\hline & & Kurt & 13.22 & 11.53 & 4.84 & 15.31 & 13.82 & 6.93 & 23.60 & 11.47 \\
\hline & & $\mathrm{ADF}$ & 100.0 & 100.0 & 100.0 & 99.9 & 100.0 & 100.0 & 99.9 & 100.0 \\
\hline & & KPSS & 100.0 & 99.8 & 98.1 & 98.4 & 99.7 & 100.0 & 96.0 & 98.6 \\
\hline
\end{tabular}

Table A.6: Entries report the descriptive statistics of CDS spreads and asset swap spreads of bonds in levels and returns. Unit root test results show the percentage of times the $H_{0}$ of the ADF are rejected and the percentage of times the $H_{0}$ of the KPSS cannot be rejected at $5 \%$. The tests have been conducted on a rolling window of width 200, leading to 1087 samples. 


\section{Appendix A.2. Generalized Variance Decompositon}

Here we develop the main steps for the in-sample variance decomposition components from Equation (5) via the impulse response function 22 Koop et al. (1996) define the generalized impulse response function GI of $\mathbf{y}_{\mathbf{t}}$ at horizon $H$ for a shock of size $\delta$ and a known history $\boldsymbol{\Omega}_{t-1}$ as follows:

$$
\mathbf{G I}\left(H, \delta, \boldsymbol{\Omega}_{t-1}\right)=E\left(\mathbf{y}_{t+H} / \mathbf{u}_{\mathbf{t}}=\delta, \boldsymbol{\Omega}_{t-1}\right)-E\left(\mathbf{y}_{t+H} / \mathbf{u}_{\mathbf{t}}=0, \boldsymbol{\Omega}_{t-1}\right)
$$

For a shock only on the $j$-th element of $\mathbf{u}_{\mathbf{t}}$, the function is written as:

$$
\mathbf{G I}_{j}\left(H, \delta_{j}, \boldsymbol{\Omega}_{t-1}\right)=E\left(\mathbf{y}_{t+H} / \mathbf{u}_{\mathbf{t j}}=\delta_{j}, \boldsymbol{\Omega}_{t-1}\right)-E\left(\mathbf{y}_{t+H} / \boldsymbol{\Omega}_{t-1}\right)
$$

In this case, the effects of the other shocks must be integrated out. For $\mathbf{u}_{t}$ normally distributed we have:

$$
E\left(\mathbf{u}_{t} / \mathbf{u}_{t j}=\delta_{j}\right)=\left(\sigma_{1 j}, \sigma_{2 j}, \cdots, \sigma_{n j}\right)^{\prime} \frac{\delta_{j}}{\sigma_{j j}}=\Sigma_{u} e_{j} \frac{\delta_{j}}{\sigma_{j j}}
$$

Thus, the generalized impulse response is given by

$$
\mathbf{G I}_{j}\left(H, \delta_{j}, \boldsymbol{\Omega}_{t-1}\right)=\mathbf{\Phi}_{H} \Sigma_{u} e_{j} \frac{\delta_{j}}{\sigma_{j j}}
$$

By setting $\delta_{j}=\sqrt{\sigma_{j j}}$ one obtains an impulse response function which measures the effect of one standard error shock to the $j$ th variable at time $t$ on the expected values of $\mathbf{y}$ at time $t+H$ :

$$
\mathbf{G I}_{j}\left(H, \delta_{j}, \boldsymbol{\Omega}_{t-1}\right)=\sigma_{j j}^{-1 / 2} \mathbf{\Phi}_{H} \Sigma_{u} e_{j}
$$

As in Pesaran and Shin (1998), this is used to derive the generalized forecast error variance decomposition components $s_{i j}^{I N}(H)$ :

$$
s_{i j}^{I N}(H)=\frac{\sigma_{j j}^{-1} \sum_{h=0}^{H-1}\left(e_{i}^{\prime} \Phi_{h} \Sigma_{u} e_{j}\right)^{2}}{\sum_{h=0}^{H-1}\left(e_{i}^{\prime} \Phi_{h} \Sigma_{u} \Phi_{h}^{\prime} e_{i}\right)}
$$

\footnotetext{
${ }^{22}$ See Hamilton (1994) for the link between impulse responses and forecast error variance decomposition.
} 
11/21/2010 (1) Ireland seeks financial support; EU-IMF package for Ireland is agreed: $12 / 02 / 2010$

04/06/2011 (2) Portugal asks for support by the Eurozone; aid to Portugal is approved: $05 / 16 / 2011$

07/15/2011 (3) Stress test results are published

07/21/2011 (4) Eurozone agrees a second bailout package for Greece

05/09/2012 (5) Spanish government rescues Bankia, which is entirely nationalized later; announcement that Spain will seek financial assistance for its banking sector: 06/09/2012; financial aid is granted: 07/20/2012.

07/26/2012 (6) Draghi promises the ECB would do "whatever it takes" to sustain the euro.

$09 / 06 / 2012$

Details of ECB's new bond-buying plan are announced.

07/04/2013 (7) ECB reveals that key interest rates would remain at present or lower levels for an extended period of time.

01/15/2014 (8) European Commission adapts Risk Finance Guidlines 4.

04/03/2014 (9) ECB states that it is disposed to apply unconventional measures such as bond purchasess or quantitative easing.

Table A.7: Timeline of important events during the European debt crisis. 


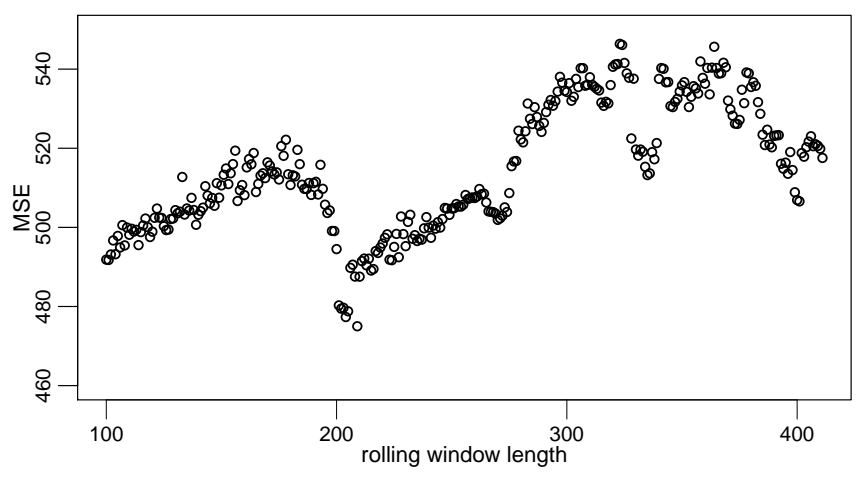

Figure A.10: Mean MSE for different window sizes

For each window length between 100 and 400, we compute MSEs across all rolling windows. The dots in the graph represent the mean of the Frobenius norm of the MSEs for each window size.

Appendix A.4.2. Parameter Constancy/Structural Breaks

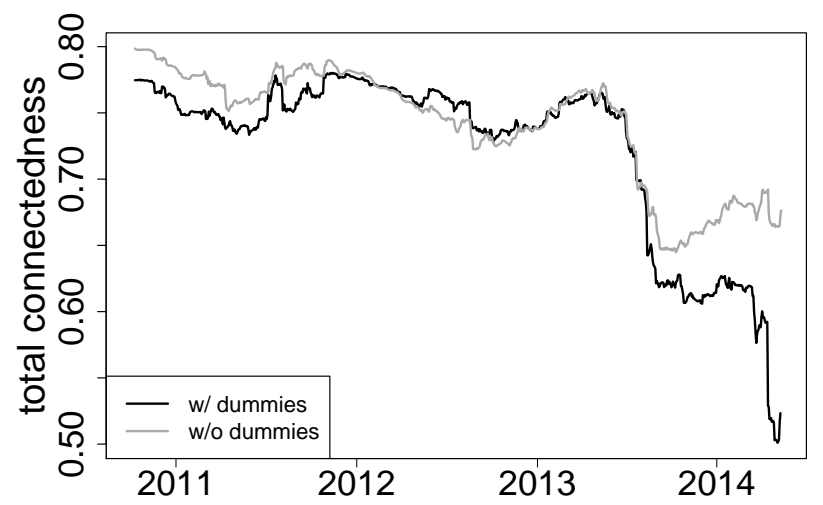

Figure A.11: Total Connectedness With and Without Time Dummies for Events

Total connectedness measures for CDS spreads with (black) and without (grey) time dummies included in the underlying VAR. Both are computed with out-of-sample forecast errors, calculated from relative measures and averaged across one, two and five forecast periods ahead. The sample covers the period from $02 / 02 / 2009$ until $05 / 02 / 2014$, which leads to out-of-sample connectedness measures from $08 / 25 / 2010$ until $05 / 02 / 2014$.

Appendix A.4.3. Heteroscedastic Effects 


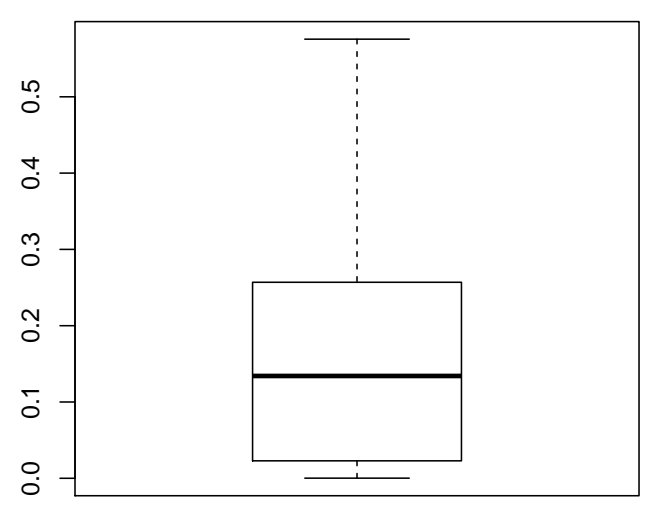

(a) Boxplot of p-values of ARCH-LMtest for all rolling windows, LM-test as proposed by Engle (1982).

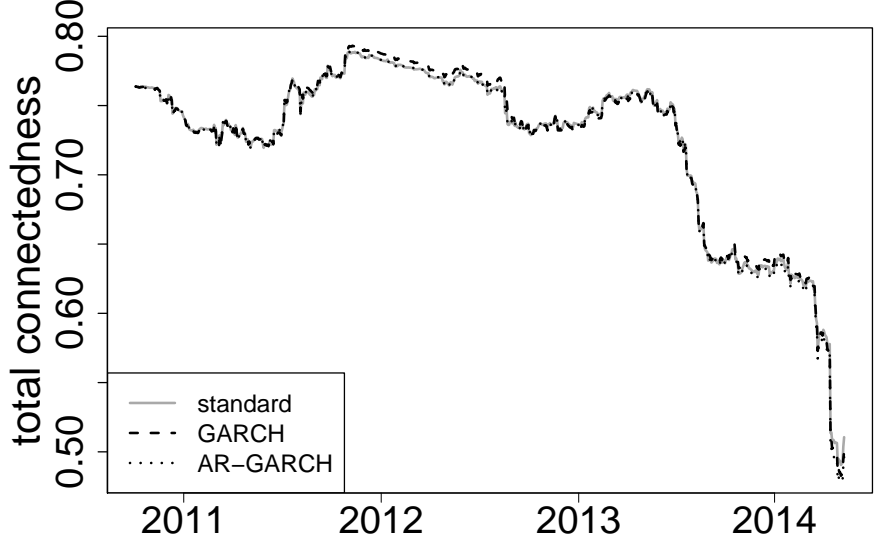

(b) Total connectedness with unfiltered data (standard), $\operatorname{GARCH}(1,1)$-filtered data and $\mathrm{AR}(1)-\mathrm{GARCH}(1,1)$ filtered data.

Figure A.12

Appendix A.4.4. VAR, VECM and VARX

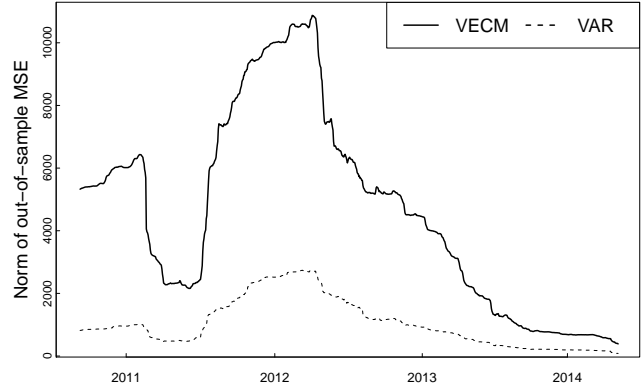

(a) Based on CDS data

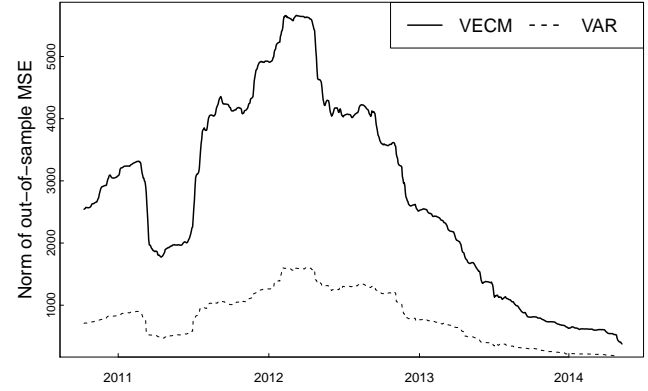

(b) Based on ASW data

Figure A.13: MSE of VECM and VAR

This figure shows the normed ${ }^{23}$ MSE of a VAR(1) and a VECM across all rolling windows, using CDS data in figure A.13a and bond data in figure A.13b. The solid line represents the normed MSE of a VECM. The number of cointegration relationships of the VECM is adapted for each estimation window. The dotted line represents the normed MSE of a $\operatorname{VAR}(1)$. The sample covers the period from 08/25/2010 until 05/02/2014.

The number of cointegration relationships of the VECM is adapted for each estimation window 


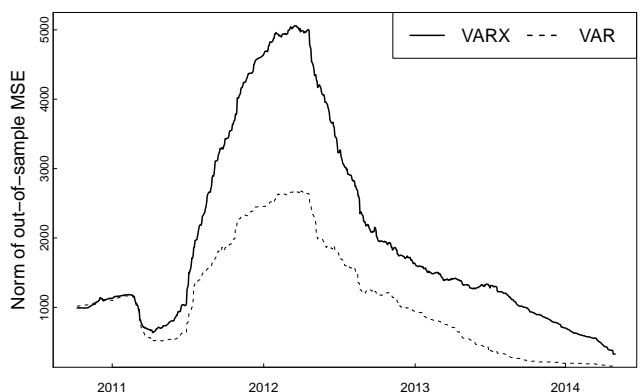

(a) using CDS data

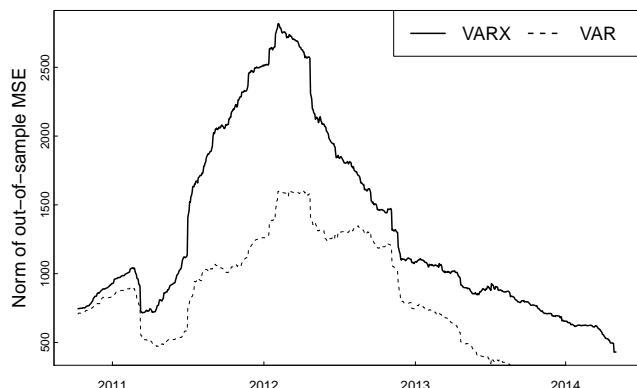

(b) using bond data

Figure A.14: MSE of VARX and VAR

This figure shows the normed MSE of a VAR(1) and a VECM across all rolling windows, using CDS data in figure A.14a and bond data in figure A.14b The solid line represents the normed MSE of a VARX including change of Euribor, VIX and iTraxx Europe as exogenous variables. VIX and iTraxx Europe are included as first differenes in order to ensure stationarity. In each estimation window, the variables are jointly significant for at least seven out of nine equations of the VARX according to the F-test. The dotted line represents the normed MSE of a VAR(1). The sample covers the period from 08/25/2010 until 05/02/2014.

\begin{tabular}{c|ccc|ccc} 
& \multicolumn{3}{|c|}{ CDS spreads } & \multicolumn{3}{c}{ Asset swap spreads } \\
\hline & VAR & VECM & VARX & VAR & VECM & VARX \\
\hline AIC & 20.48 & 20.66 & 20.48 & 25.09 & 25.26 & 25.08 \\
BIC & 22.03 & 23.28 & 22.03 & 26.42 & 27.66 & 26.40 \\
logLik & -4186 & -4084 & -4187 & -4648 & -4557 & -4649
\end{tabular}

Table A.8: AIC, BIC and log-Likelihood of a selection of models

For each rolling window in our samples we compute the AIC, BIC and log-Likelihood of different estimated models. Entries report the average values of AIC, BIC and log-Likelihood across all estimation windows. 
Appendix A.5. Panel Regression Results

\begin{tabular}{|c|c|c|c|}
\hline & Variable & Estimate & Std. Dev. \\
\hline \multirow{5}{*}{ 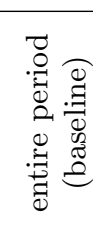 } & Bid-ask CDS & -4.56 & $(1.89)^{*}$ \\
\hline & Bid-ask ASW & 1.17 & $(2.74)$ \\
\hline & Debt/GDP & 0.00 & $(0.00)$ \\
\hline & VIX & 0.05 & $(0.02)^{*}$ \\
\hline & Euribor-Eurepo & 0.12 & $(0.25)$ \\
\hline \multirow{6}{*}{ 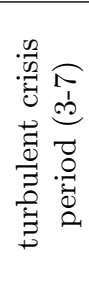 } & Dummy constant & 0.54 & $(0.24)^{*}$ \\
\hline & $\mathrm{D} *$ Bid-ask CDS & 3.61 & $(0.91)^{* * *}$ \\
\hline & D * Bid-ask ASW & 9.19 & $(2.03)^{* * *}$ \\
\hline & $\mathrm{D} *$ Debt/GDP & 0.00 & $(0.00)$ \\
\hline & $\mathrm{D} * \mathrm{VIX}$ & -0.03 & $(0.01)^{*}$ \\
\hline & D * Euribor-Eurepo & 0.15 & $(0.13)$ \\
\hline
\end{tabular}

(a) Estimates and Standard Deviations

\begin{aligned} \hline Country & Fixed Effect \\ \hline Netherlands & 0.57 \\ Belgium & 0.48 \\ Spain & 0.45 \\ France & 0.38 \\ Germany & 0.37 \\ Ireland & 0.37 \\ Italy & 0.37 \\ Portugal & 0.29\end{aligned}

(b) Country Fixed Effects in Levels

Table A.9: Panel Regression Results for CDS connectedness

Table A.9a lists the coefficient estimates and standard deviations for the panel regression of connectedness computed with CDS data including fixed effects, using 785 observations of nine countries. The numbers in parentheses are robust standard errors and ***, **,* indicate significance at the $0,1 \%, 1 \%$, and $5 \%$ level. The within adjusted R-squared is 0.79 and the coefficients are jointly significant with an F statistic of 2160.36 . Since the difference in connectedness is computed on a 200 day rolling window, we use rolling window estimates of the same width for the regressors. We use a time dummy for the most turbulent period of the crisis between 07/15/2011 (event 3) and 07/04/2012 (event 7). In the second block titled "between (3) and (7)" we list the estimates of the interaction terms. Standard errors are robust to serial correlation and cross-sectional correlation according to Driscoll and Kraay (1998)

Countries in Table A.9b are ordered by size of the fixed effect.

\begin{tabular}{|c|c|c|c|}
\hline & Variable & Estimate & Std. Dev. \\
\hline \multirow{5}{*}{ 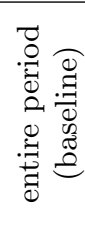 } & Bid-ask CDS & -1.94 & $(0.38)^{* * *}$ \\
\hline & Bid-ask ASW & -0.31 & $(1.17)$ \\
\hline & Debt/GDP & 0.00 & $(0.00)$ \\
\hline & VIX & 0.01 & $(0.01)$ \\
\hline & Euribor-Eurepo & -0.07 & $(0.05)$ \\
\hline \multirow{6}{*}{ 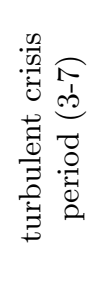 } & Dummy constant & 0.23 & $(0.16)$ \\
\hline & $\mathrm{D} *$ Bid-ask CDS & 0.44 & $(0.34)$ \\
\hline & $\mathrm{D} *$ Bid-ask ASW & 3.13 & $(0.53)^{* * *}$ \\
\hline & $\mathrm{D} *$ Debt/GDP & 0.00 & $(0.00)$ \\
\hline & $\mathrm{D} * \mathrm{VIX}$ & -0.01 & $(0.00)^{*}$ \\
\hline & D * Euribor-Eurepo & -0.09 & $(0.11)$ \\
\hline
\end{tabular}

(a) Estimates and Standard Deviations

\begin{aligned} & \hline Country Fixed Effect \\ & \hline Italy 1.36 \\ & Spain 1.32 \\ & Belgium 1.30 \\ & Ireland 1.20 \\ & Portugal 1.20 \\ & France 1.19 \\ & Netherlands 1.19 \\ & Germany 1.11 \\ & \hline\end{aligned}

(b) Country Fixed Effects in Levels

Table A.10: Panel Regression Results for ASW connectedness

Explanation as in Table A.9a with outgoing asset swap connectedness as dependent variable. The within adjusted R-squared is 0.42 and the coefficients are jointly significant with an F statistic of 429.55. 
Appendix A.6. Networks

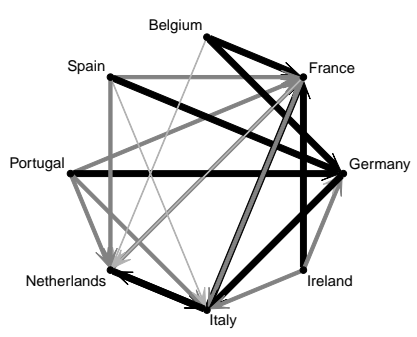

(a) $05 / 13 / 2011$, CDS

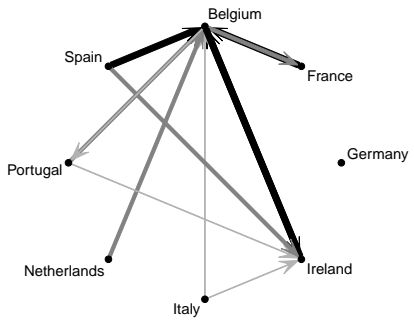

(d) 05/13/2011, ASW

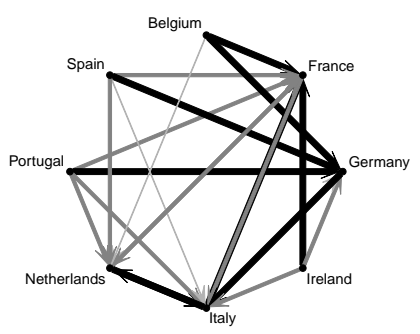

(b) $05 / 16 / 2011$, CDS

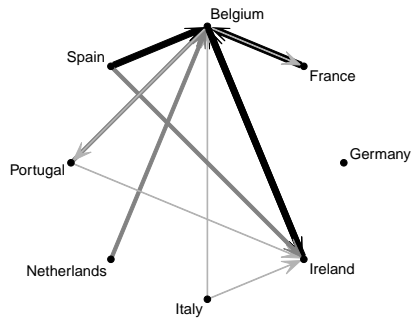

(e) $05 / 16 / 2011, \mathrm{ASW}$

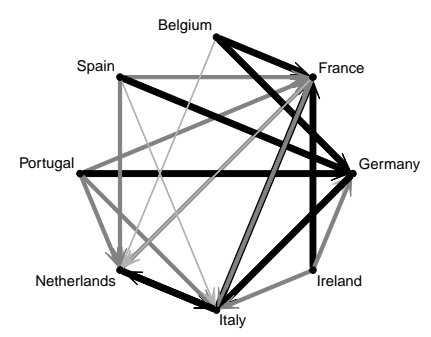

(c) $05 / 17 / 2011$, CDS

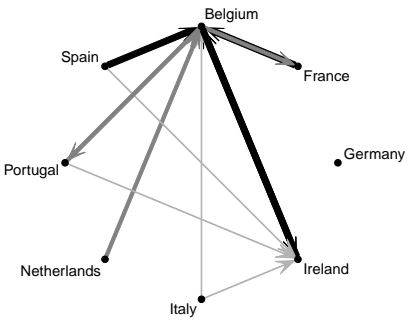

(f) $05 / 17 / 2011, \mathrm{ASW}$

Figure A.15: Difference between out-of-sample and in-sample connectedness one day before ((a), (d)), at ((b),(e)) and one day after ((c),(f)) the bailout of Portugal. Figures (a)-(c) are computed using CDS data, while Figures (d)-(f) are based on asset swap data. The same definitions as in Figure 3 apply.

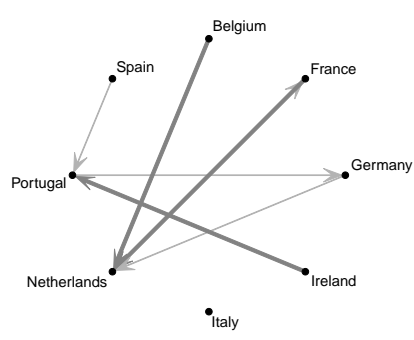

(a) $09 / 05 / 2012, \mathrm{CDS}$

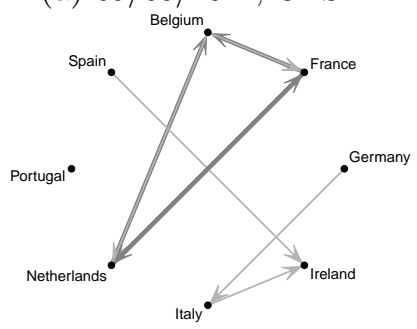

(d) $09 / 05 / 2012, \mathrm{ASW}$

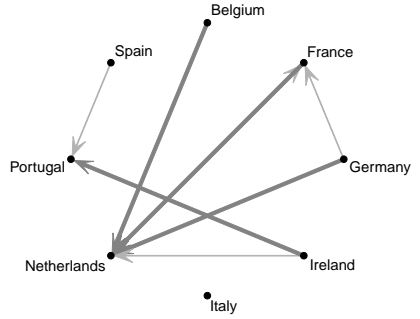

(b) $09 / 07 / 2012$, CDS

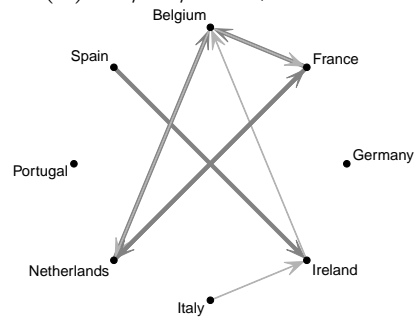

(e) $09 / 07 / 2012, \mathrm{ASW}$

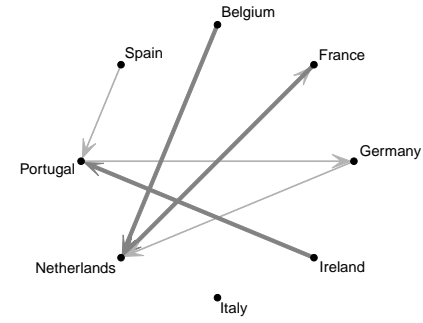

(c) $09 / 10 / 2012, \mathrm{CDS}$

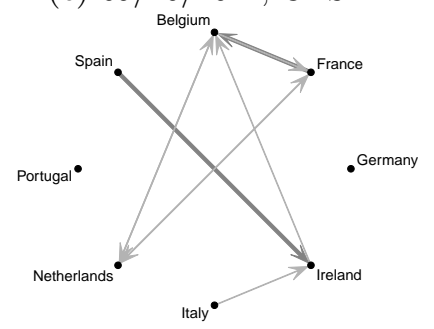

(f) $09 / 10 / 2012, \mathrm{ASW}$

Figure A.16: Difference between out-of-sample and in-sample connectedness one day before ((a),(d)), at ((b),(e)) and one day after ((c),(f)) the announcement of the OMT. Figures (a)-(c) are computed using CDS data, while Figures (d)-(f) are based on asset swap data. The same definitions as in Figure 3 apply. 


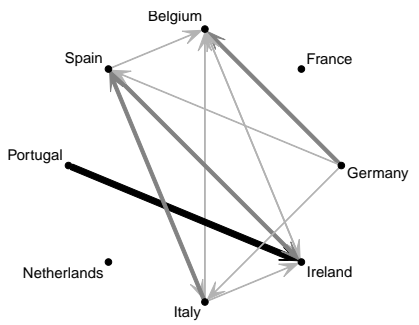

(a) $07 / 20 / 2011$, ASW

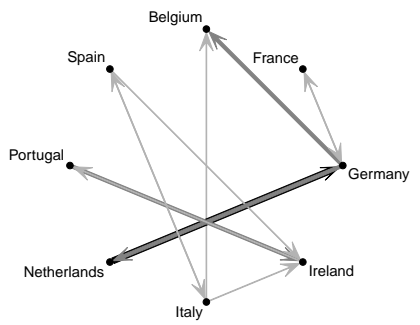

(b) $07 / 21 / 2011, \mathrm{ASW}$

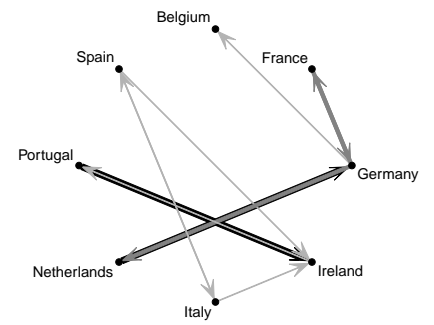

(c) $07 / 22 / 2011, \mathrm{ASW}$

Figure A.17: Differences between out-of-sample and in-sample connectedness during second bailout for Greece using ASW data. The same definitions as in Figure 3 are applied.

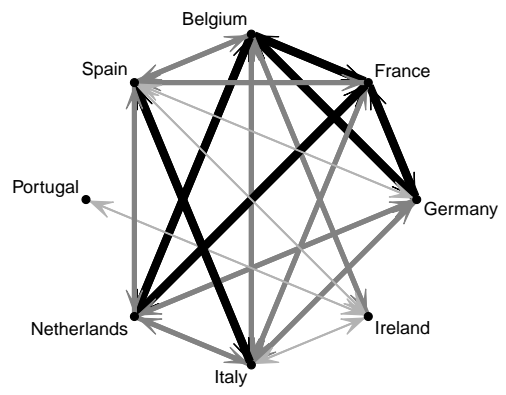

(a) $07 / 25 / 2012$, absolute, CDS

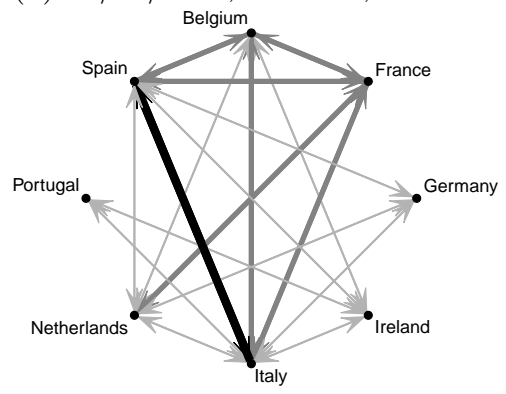

(c) $07 / 25 / 2012$, absolute, ASW

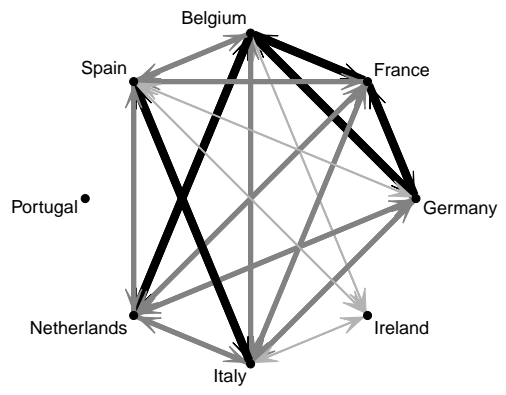

(b) $09 / 07 / 2012$, absolute, CDS

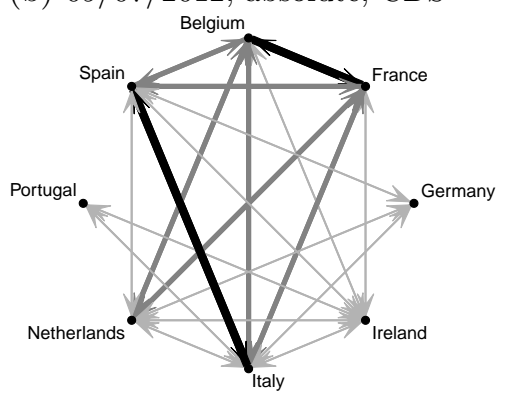

(d) 09/07/2012, absolute, ASW

Figure A.18: Absolute connectedness before Draghi's speach (07/25/2012) and after the announcement of the OMT (09/07/2012) using asset swap spreads. The same definitions as in Figure 3 apply. 


\section{Working Paper Series in Economics}

recent issues

No. 123 Rebekka Buse and Melanie Schienle: Measuring connectedness of euro area sovereign risk, January 2019

No. 122 Carsten Bormann and Melanie Schienle: Detecting structural differences in tail dependence of financial time series, January 2019

No. 121 Christian Conrad and Melanie Schienle: Testing for an omitted multiplicative long-term component in GARCH models, January 2019

No. 120 Marta Serra-Garcia and Nora Szech: The (in)elasticity of moral ignorance, December 2018

No. 119 Thomas Mariotti, Nikolaus Schweizer, Nora Szech and Jonas von Wangenheim: Information nudges and self-control, November 2018

No. 118 Andranik S. Tangian: Methodological notes on composite indicators for monitoring working conditions, October 2018

No. 117 Andranik S. Tangian: Testing the improved third vote during the 2018 election of the Karlsruhe Institute of Technology student parliament, September 2018

No. 116 Yuri Golubev and Mher Safarian: On robust stopping times for detecting changes in distribution, May 2018

No. 115 Daniel Hoang, Sebastian Gatzer and Martin Ruckes: The economics of capital allocation in firms: Evidence from internal capital markets, January 2018

No. 114 Francesco D'Acunto, Daniel Hoang and Michael Weber: Unconventional fiscal policy, January 2018

No. 113 Alberto Bucci, Levent Eraydın, Moritz Müller: Dilution effects, population growth and economic growth under human capital accumulation and endogenous technological change, January 2018 